\title{
Scientific Concepts of Functional Foods in Europe Consensus Document
}

\section{PREFACE \\ ILSI Europe's role}

The European Commission Concerted Action on Functional Food Science in Europe (FUFOSE), which is co-ordinated by The International Life Sciences Institute - ILSI Europe, aims to establish a science-based approach for concepts in functional food science. The goal of this Concerted Action has been to set up a multidisciplinary European network:

1. to assess critically the science base required to provide evidence that specific nutrients and food components positively affect target functions in the body;

2. to examine the available science from a function-driven perspective rather than a product-driven one; and

3. to reach consensus on targeted modifications of food and food constituents, and options for their application.

This approach led to identifying key partners from Europe's food and agricultural industry, governmental and intergovernmental bodies and the scientific community. This project provided them with an opportunity to exchange ideas and to interact on a neutral platform.

\section{Theme groups for physiological functions}

The First Plenary Meeting on Functional Food Science in Europe: State of the Art was held in Nice, France, in April 1996. Based on the results of this meeting, six major areas in human physiology were selected and corresponding Individual Theme Groups (ITG) were set up and charged with producing theme papers to review critically the science base of the concepts in their respective areas:

- Growth, development and differentiation: a functional food science approach.

- Functional food science and substrate metabolism.

- Functional food science and defence against reactive oxidative species.

- Functional food science and the cardiovascular system.

- Functional food science and gastrointestinal physiology and function.

- Functional food science and behaviour and psychological functions.

Each ITG reviewed the published literature to: define the state of the art with respect to specific body systems; assess critically methodologies to characterize and quantify specific related functions; identify and review nutritional options modulating these functions; evaluate potential safety implications related to these nutritional options; identify the role of food technology on nutritional and safety aspects; assess critically the science-base required for providing evidence that specific nutrients positively affect functions; identify areas where further research is required.

The resulting documents were scrutinized in a Second Plenary Meeting held in July 1997 in Helsinki, Finland, and revised by the ITG chairs to include the comments made during that consultation. The final reports of the six ITGs were published in the British Journal of Nutrition (Bellisle et al. 1998).

\section{Theme group for technology}

An Expert Group on Food Technology was also established to examine the impact and feasibility of food technology on functional food development. Bearing in mind that a function-driven approach rather than a product-driven approach should be adopted, the group considered examples of technologies that are applied to raw materials to improve their quality, the identification of new materials and new processes, and the interactions between processing and functionality.

The group reviewed the impact of food processing on themes such as technological processes to optimize antioxidants, minerals, micro-organisms, carbohydrates and peptides.

The Technology Theme Group was asked to address topics such as the state of the art (impact of processing); source of materials; processing options modulating functionality, including post-harvest technology, unit operations and storage and distribution/packaging; safety implications of materials and processes; process monitoring for functions; and further development and research needs.

These five technology theme papers have been published in Trends in Food Science and Technology (Knorr et al. 1998).

\section{Concept of the Consensus Document}

The six ITG reviews and that of the Technology Group provided the foundation for this Consensus Document on Scientific Concepts of Functional Foods in Europe. The outline for the document was reviewed by participants at the Second Plenary Meeting in Helsinki, Finland.

The draft document was reviewed by the Steering Committee set up to monitor this project, as well as the ILSI Europe Functional Food Task Force, and by the participants in the Third Plenary Meeting, which was held in Madrid in October 1998. Their comments have all been taken into consideration in this final Consensus Document.

The text of the document, which follows, will make constant reference to the six ITG papers as well as those from the Technology Group. Readers who require further 
details and full references are advised to consult the original documents in the British Journal of Nutrition (Bellisle et al. 1998) and in Trends in Food Science and Technology (Knorr et al. 1998). It should be emphasized that the intention of this Consensus Document was to select specific examples to highlight some aspects of the subjects covered. It was not the intention for it to be a comprehensive and exhaustive account.

It also must be borne in mind that the subjects of the ITGs were identified on the basis that they represented most, but not all, of the important physiological functions related to this field. The exclusion of subjects in these papers should not be taken to indicate that they are unimportant. Because scientific knowledge is continually advancing, the Consensus Document cannot pretend to be totally up to date. Nevertheless, it has been based on the most recent data available at the time of writing (published up to the end of 1997).

\section{Structure of the Consensus Document}

After the introductory Section 1 of this Consensus Document, Section 2 will outline the aims of functional food science and will introduce some important considerations about classification and criteria for markers of target functions, which play a major role in health.

Section 3 will consider each of the areas of physiological function reviewed in the six ITG papers and will highlight some of the key target functions with examples of relevant markers wherever possible. Also included in the consideration are the options for application (i.e. how the target functions could be modulated positively by components within functional foods), as well as proposals for research opportunities.

Section 4 of this document will consider how food technology can play an important role in the development of functional foods and will draw on examples of key technological challenges from the five areas covered in the technology theme papers. Research opportunities that could help to meet the challenges will be indicated.

Finally, Section 5 of this Consensus Document deals with the communication of health benefits to the public and the principles, definitions, use and scientific basis of claims. Although this area is primarily a regulatory concern and not within the mandate of ILSI as a scientific organization, we recognize that communication of health benefits is an essential element in improving public health in which science plays a vital role. This section offers a brief overview, using examples of types of claims and of local regulatory philosophies and approaches. The aim is to explain/highlight the differences in claims and approaches based on nutritional, physiological or pathophysiological scientific knowledge. This EU Concerted Action has allowed the development of ideas that suggest an innovative way in which to link the science of functional foods with the communication about their possible benefits to consumers.

The Executive Summary, which includes the Recommendations of the Consensus Document, is found in Section 6, and the Key Messages are summarized in Section 7.

The following scientists reviewed and agreed on the text of this Consensus Document:

Prof. P. J. Aggett
Prof. J. Alexander
Mrs M. Alles
Dr P. A. Anderson
Dr J.-M. Antoine
Dr M. Ashwell
Prof. N.-G. Asp
Prof. C. A. Barth
Prof. B. Beaufrère
Dr F. Bellisle
Prof. P. A. Biacs
Dr J. G. Bindels
Dr N. M. Binns
Prof. J. E. Blundell
Mrs J. Booth
Dr F. Bornet
Prof. A. Bruce
Dr L. Contor
Dr B. Danse
Prof. A. T. Diplock
Mrs S. Doyran
Prof. I. Elmadfa
Dr E. Fern
Mr R. J. Fletcher
Dr A. Franck
Dr F. Guarner
Dr F. Guillon
Mrs C. Guittard

Prof. P. J. Aggett

Mrs M. Alles

Dr P. A. Anderson

Dr J.-M. Antoine

Dr M. Ashwell

Prof. N.-G. Asp

Prof. C. A. Barth

Prof. B. Beaufrère

Dr F. Bellisle

Prof. P. A. Biacs

Dr J. G. Bindels

Dr N. M. Binns

Prof. J. E. Blundell

Dr. Bornet

Prof. A. Bruce

Dr L. Contor

Dr B. Danse

Prof. A. T. Diplock

Prof. I. Elmadfa

Dr E. Fern

Mr R. J. Fletcher

Dr F. Guarner

Mrs C. Guittard
University of Central Lancashire

National Institute of Public Health

Borculo Whey Products

ILSI North America

Groupe Danone

Ashwell Associates

University of Lund

German Institute for Human Nutrition

University of Auvergne

INSERM

KEKI - Central Food Research Institute

Numico Research

Coca-Cola Greater Europe

University of Leeds

St Ivel

Eridania Béghin-Say

National Food Administration

ILSI Europe

ILSI Europe

International Antioxidant Research Centre

FAO - Food and Agriculture Organization

University of Vienna

Nestlé

Kellogg

Raffinerie Tirlemontoise

General Hospital Vall d'Hebron

INRA

Monsanto

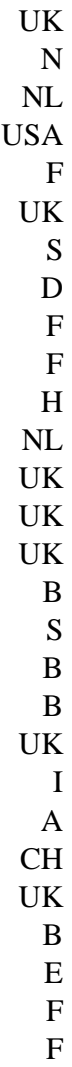




\begin{tabular}{|c|c|c|}
\hline Dr W. Haehnlein & BASF & D \\
\hline Dr B. Hanley & CSL - Food Science Laboratory & UK \\
\hline Prof. J. Hautvast & Wageningen Agricultural University & NI \\
\hline Dr T. Hirahara & ILSI Japan & \\
\hline Mr J. R. Hislop & Procter \& Gamble & \\
\hline Prof. G. Hornstra & Maastricht University & \\
\hline Dr J. Howlett & Cultor Food Science & $\mathrm{U}$ \\
\hline Prof. J. Huis in't Veld & Yakult Europe & $\mathrm{N}$ \\
\hline Prof. D. Knorr & Berlin University of Technology & \\
\hline Prof. F. J. Kok & Wageningen Agricultural University & \\
\hline Prof. B. Koletzko & Ludwig-Maximilian University Munich & \\
\hline Prof. H. Korhonen & Food Research Institute & \\
\hline Mrs R. Korpela & Valio & \\
\hline Dr J. Kruseman & Nestlé & $\mathrm{CH}$ \\
\hline Dr J. Lambert & Mars & UK \\
\hline Dr M. G. Lindley & University of Reading & $\mathrm{U}$ \\
\hline Dr J. Lucas & European Commission - DG XII & \\
\hline Dr G. Malgarini & Ferrero Group & \\
\hline Dr M. N. Meah & MAFF & UK \\
\hline Ms A. Michel-Drees & German Food Office & \\
\hline Dr D. J. G. Müller & Procter \& Gamble & \\
\hline Ms B. Nielsen & F. Hoffman-La Roche & $\mathrm{Cl}$ \\
\hline Dr H. Nordmann & Monsanto & $\mathrm{CH}$ \\
\hline Dr L. Ovesen & Danish Veterinary and Food Administration & $\mathrm{D}$ \\
\hline Dr G. Pascal & CNERNA & \\
\hline Dr A. L. J. Peters & Cosun/Sensus & $\mathrm{N}$ \\
\hline Prof. G. Riccardi & University of Naples & \\
\hline Prof. M. Roberfroid & Catholic University of Louvain (UCL) & \\
\hline Prof. S. Salminen & University of Turku & \\
\hline Prof. W. H. M. Saris & Maastricht University & \\
\hline Dr A. M. Stephen & University of Saskatchewan & $\mathrm{CDN}$ \\
\hline Dr O. Tello-Anchuela & National Centre for Epidemiology & \\
\hline Ir. E. Timmermans & Borculo Whey Products & \\
\hline Mr R. Top & Ministry Public Health, Well-being and Sport & \\
\hline Dr H. van den Berg & TNO & \\
\hline Drs P. M. Verschuren & Unilever Research Vlaardingen & \\
\hline Dr S. Videla & General Hospital Vall d'Hebron & \\
\hline Dr V. Viechtbauer & Red Bull & \\
\hline Prof. B. Viell & $\mathrm{BgVV}$ & \\
\hline Dr M. Vogel & Südzucker & \\
\hline Prof. A. G. J. Voragen & Wageningen Agricultural University & \\
\hline Prof. P. Walter & University of Basel & \\
\hline Dr D. A. Whitmore & Novartis & \\
\hline Mr D. Wils & Roquette Frères & \\
\hline Dr M. J. Wiseman & Department of Health & \\
\hline
\end{tabular}

\section{Acknowledgements}

We wish especially to thank all of the individual contributors to this project and Consensus Document for devoting their time and efforts within the required timeframe. Their continuous willingness to ensure the success of this Concerted Action has been sincerely appreciated and ILSI Europe, as co-ordinator of this Concerted Action, is extremely grateful to all of them.

\section{Co-ordinators}

\section{Co-ordinator:}

Dr Berry Danse, ILSI Europe, 83 Avenue E. Mounier, Box 6, B-1200 Brussels, Belgium.
Scientific co-ordinator:

Prof. Marcel Roberfroid, Catholic University of Louvain, Ecole de Pharmacie, Tour Van Helmont, 73 Avenue E. Mounier, B-1200 Brussels, Belgium.

EC responsible:

Dr Liam Breslin, Agro-industrial Research, Food, Commission of the European Communities, Directorate-General XII, Science, Research and Development, 200 Rue de la Loi, B-1049 Brussels, Belgium.

\section{Project manager:}

Dr Laura Contor (for further information), ILSI Europe, 83 Avenue E. Mounier, Box 6, B-1200 Brussels, Belgium. Tel. +32-2 771.00.14 Fax +32-2 762.00.44 


\begin{abstract}
About ILSI
The International Life Sciences Institute (ILSI) is a nonprofit, world-wide foundation established in 1978 to advance the understanding of scientific issues related to nutrition, food safety, toxicology and the environment. By bringing together scientists from academia, government, industry and the public sector, ILSI seeks a balanced approach to solving problems with broad implications for the benefit of the general public. ILSI is affiliated with the World Health Organization as a non-governmental organization and has specialized consultative status with the Food and Agriculture Organization of the United Nations. Headquartered in Washington, DC, USA, ILSI has branches in Argentina, Australasia, Brazil, Europe, India, Japan, Korea, Mexico, North Africa and the Gulf Region, North America, South Africa, the South Andean region, Southeast Asia and Thailand, and a Focal Point in China. Today, ILSI enjoys the support of around 300 companies and a network of scientists throughout the world.
\end{abstract}

\section{About ILSI Europe}

In 1986, ILSI Europe was created to focus on the specific needs defined by the Institute's European partners.

The main goals of ILSI Europe are to:

- foster scientific advances by promoting collaboration among scientific experts in industry, academia, and national and international regulatory bodies;

- provide coherent scientific answers to scientific issues of common concern for the well-being of the general public;

- support an active publication programme for the dissemination of scientific information to the broadest possible audience including the scientific community, international organizations and regulatory agencies.

To address these issues, ILSI Europe's members initiate projects, which are managed by specific task forces. Task forces accomplish their goals through activities such as research, workshops, conferences and publications.

\section{About the European Commission FAIR RTD programme}

This concerted action 'Functional Food Science in Europe' (FUFOSE) has been funded within the FAIR RTD programme, which is part of the Commission's Fourth Framework Programme for research and technological development.

This programme aims at promoting trans-European research in the primary production sectors of agriculture, horticulture, forestry, fisheries and aquaculture, linking these with the input and processing industries, particularly food processing and renewable biomaterials.

The food area is important within this programme and is covered by the theme 'Generic Science and Advanced Technologies for Nutritious Foods'.

There is growing interest in Europe in the concept of 'Functional Foods' and this Concerted Action, bringing together Europe's scientists and industry, is fundamental to establishing a science-based approach to such foods. 


\section{INTRODUCTION}

\subsection{From traditional to new concepts in nutrition}

The primary role of diet is to provide sufficient nutrients to meet the metabolic requirements of an individual and to give the consumer a feeling of satisfaction and well-being through hedonistic attributes such as taste. However, in addition to this there is evidence to support the hypothesis that, by modulating specific target functions in the body, diet can have beneficial physiological and psychological effects beyond the widely accepted nutritional effects. In fact, diet can not only help to achieve optimal health and development, but it might also play an important role in reducing the risk of disease.

We are at a new frontier in nutrition science because, at least in the industrialized world, concepts in nutrition are changing significantly. We are progressing from a concept of 'adequate nutrition' to one of 'optimal nutrition'. We have moved from a former emphasis on survival, through one of hunger satisfaction and of food safety, to our present emphasis on the potential for foods to promote health, in terms of both improving well-being (mental and physical conditioning) and reducing the risk of diseases.

Although there are still many people who know little nutrition science, consumer awareness of the subject and its relationship to health is, nevertheless, growing appreciably. Almost everyone today is more conscious of and better informed about the subject than they were in the past. As a result, their expectations of obtaining health benefits from the food they consume is increasing. In a recent survey of 14331 people interviewed in all 15 Member States of the European Union, $9 \%$ chose 'eating healthily' as the most important influence in selecting food and $32 \%$ said that this had some influence of their food choice (Institute of European Food Studies, 1996).

\subsection{From the importance of improving life expectancy to the importance of quality of life}

The changing concepts in nutrition are of particular importance in view of some significant trends in our present society. They are:

1. The increasing cost of health care and of days lost from work.

2. The continuing increase in life expectancy.

3 . The increase in the numbers of elderly people.

4. The desire of people for an improved quality of life.

The rising cost of health care is of primary concern in many parts of the world. The cost of health care in European countries in 1995 was estimated to be, on average, around $8 \%$ of the gross domestic product, approximately one percentage point higher than it was a decade ago.

Life expectancy in virtually every country of the world is higher today than it has ever been for all age groups - from birth as well as at later ages. Expectation of life from birth for both men and women is highest in Japan, but is followed closely by a number of European countries. Furthermore, the rate of increase in life expectancy appears to show no sign of declining.
Associated with this increase in life expectancy is the growth in the size of the population above the age of 65 years. In Europe the relative proportion is currently between $14-17 \%$ of the total population and several European countries have the highest population of elderly people in the world. This figure is expected to rise to between 20 $24 \%$ in the next 30 years.

An improved quality of life must accompany this improved life expectancy and increase in the elderly population if relative health care costs can ever be better controlled and managed.

\subsection{From new concepts in nutrition to functional foods}

The wide range of food products available to today's consumer offers a wide variety of complex food components, both nutritive and non-nutritive. These have the potential to improve the health and well-being of individuals and, maybe, to reduce the risk from, or delay the development of, major diseases such as cardiovascular disease (CVD), cancer and osteoporosis.

Advances in food science and technology are now providing the food industry with increasingly sophisticated methods to control and alter the physical structure and the chemical composition of food products. There is now a growing realization of the market potential for functional foods, based on the principle of added value linked to health benefit.

\subsection{International developments relating to functional foods}

The new concepts in nutrition outlined in Section 1.1 have, over the last 10-12 years, justified the efforts of health authorities in many countries, especially in Japan and in the United States of America, to stimulate and support research on physiological effects of food components and their health benefits. They have also been a major factor in the reconsideration of their regulatory policy on foods and health claims.

In Japan, research on functional foods began in the early 1980s, when 86 specified programmes on 'Systematic analysis and development of food functions' were funded by the government. Later, the Ministry of Education sponsored additional focal point studies on "Analysis of physiological regulation function of food' and 'Analysis of functional foods and molecular design'. Then, in 1991, the concept of Foods for Specified Health Use (FOSHU) was established. These foods are included as one of the four categories of foods, described in the 'Nutrition Improvement Law' as 'Foods for special dietary use' (i.e. 'foods that are used to improve people's health and for which specific health effects are allowed to be displayed'). Upon satisfactory submission of comprehensive data documenting the scientific evidence in support of a proposed health claim, the Minister of Health and Welfare is able to approve a claim, and grant permission, to use a 'symbol' on labelling, to indicate to the consumer that the health claim has government approval.

Foods identified as FOSHU are required to provide evidence that the final food product is expected to exert a 
health or physiological effect; data on the effects of isolated individual components are not sufficient. FOSHU products should be in the form of ordinary foods (i.e. not as pills or capsules) and are assumed to be consumed as part of an ordinary diet (i.e. not as very occasional items linked to specific symptoms). Most FOSHU products currently approved contain either oligosaccharides or lactic acid bacteria for promoting intestinal health.

In the United States of America, 'reduction of disease risk' claims have been allowed since 1993 on certain foods. These contain components where the Food and Drug Administration (FDA) has accepted there is objective evidence for a correlation between nutrients or foods in the diet and certain diseases on the basis of 'the totality of publicly available scientific evidence, and where there is substantial agreement amongst qualified experts that the claims were supported by the evidence'. By 1998 there were eleven FDA-approved correlations between foods, or components, and diseases. These are claims for the relationship between foods that are high in calcium and the reduced risk of osteoporosis; claims for foods that are low in saturated fats, low in cholesterol and low in fat and the reduced risk of coronary heart disease; and the claim for sugar alcohols in relation to reduced risk of dental caries. The claim relating diets containing soluble fibre with the reduced risk of coronary heart disease has been amended twice to allow claims for the soluble fibre from whole oats and from psyllium seed husk. Very recently, the FDA has announced that claims can also be based on 'authoritative statements' of a Federal Scientific Body, such as the National Institute of Health and Center for Disease Control, as well as from the National Academy of Sciences, as allowed by the FDA Modernization Act of 1997.

In the European Union, there is no harmonized legislation on health claims, which means that they are dealt with at a national level. However, it is well recognized that the competitive position of the European food and drink industry should be reinforced through a better understanding of the scientific basis for the functionality of food.

A self-regulating programme on health claims was introduced in Sweden in 1990 and revised in 1996. It permits claims with two parts: information on one of eight approved diet-health relationships, followed by information on the composition of the product (function-based claims). The accepted conditions are obesity (energy), blood cholesterol (fat quality), blood pressure (sodium), atherosclerosis (blood pressure, serum cholesterol, long-chain n-3 polyunsaturated fatty acids (PUFA) in fish), constipation (dietary fibre), osteoporosis (calcium), dental caries (easily fermentable carbohydrates) and iron deficiency (iron). The food industry and retail organizations behind the programme have recently suggested an extension to cover product-specific physiological claims, characteristic of functional foods.

\subsection{From functional foods to functional food science}

Up to now, the approaches used for functional food science, both in Japan and to a lesser extent in the USA, to match these new concepts in nutrition have mostly been 'product or food component-driven', and they are likely to be very much influenced by local, traditional or cultural characteristics. A science-based, 'function-driven' approach is preferable, because the functions and their modulation are universal. Functional food science, therefore, refers to the new concepts in the science of nutrition that lead to the stimulation of research and to the development of functional foods.

\subsubsection{Working definitions}

No universally accepted definition for functional foods exists. In fact, because functional foods are more of a concept than a well-defined group of food products, a working definition rather than a firm definition is preferred for the purposes of this Consensus Document.

A food can be regarded as 'functional' if it is satisfactorily demonstrated to affect beneficially one or more target functions in the body, beyond adequate nutritional effects, in a way that is relevant to either an improved state of health and well-being and/or reduction of risk of disease. Functional foods must remain foods and they must demonstrate their effects in amounts that can normally be expected to be consumed in the diet: they are not pills or capsules, but part of a normal food pattern.

A functional food can be a natural food, a food to which a component has been added, or a food from which a component has been removed by technological or biotechnological means. It can also be a food where the nature of one or more components has been modified, or a food in which the bioavailability of one or more components has been modified, or any combination of these possibilities. A functional food might be functional for all members of a population or for particular groups of the population, which might be defined, for example, by age or by genetic constitution.

\subsubsection{The functional food science approach for Europe}

The design and development of functional foods is a key issue, as well as a scientific challenge, which should rely on basic scientific knowledge relevant to target functions and their possible modulation by food components. Functional foods themselves are not universal, and a food-based approach would have to be influenced by local considerations. In contrast, a science-based approach to functional food is universal and, because of this, is very suitable for a pan-European approach. The function-driven approach has the science base as its foundation - in order to gain a broader understanding of the interactions between diet and health. Emphasis is then put on the importance of the effects of food components on well-identified and well-characterized target functions in the body that are relevant to health issues, rather than solely on reduction of disease risk.

\section{THE SCIENTIFIC BASIS OF FUNCTIONAL FOODS}

\subsection{The aims of functional food science}

Knowledge of the mechanism(s) by which functional food(s) can modulate the target function(s) and their 
relevance to the state of well-being and health and/or reduction of a disease will originate from basic knowledge in the biological sciences. It might also be supported by epidemiological data that could demonstrate a statistically validated and relevant relationship between the intake of individually specified food components (better still, a serum, faecal, urinary or tissue marker of intake of the components under study) and the specific benefit. Furthermore, it will be of particular value to have good prospective evidence that links the habitual intake of specified food components with the reduction of the risk of disease, which might develop some time later.

The aims of functional food science are, therefore, as follows:

- To identify beneficial interaction(s) between a functional component within a food and one or more target functions in the body and to obtain evidence for the mechanism(s) of these interactions. (Results from studies carried out in vitro, in cells in culture, the use of in vitrolex vivo models and animal models, as well as results from human studies, should be included.)

- To identify and validate markers relevant to these functions and their modulation by food components (see below).

- To assess the safety of the amount of food or its component(s) needed for functionality. This will require evidence that is equally applicable to all major groups in the population, including those who are indulging in behaviour that might be expected to compromise the anticipated benefits of the functional food. It might involve post-marketing monitoring, including the effects on the whole diet.

- To formulate hypotheses to be tested in human intervention trials that aim to show that the relevant intake of specified food components is associated with improvement in one or more target functions, either directly, or in terms of a valid marker of an improved state of health and well-being and/or a reduced risk of a disease.

\subsection{Target functions for health outcomes}

This Consensus Document on 'functional food science' does not intend to summarize the science and the technology theme papers. Rather, its aim is to illustrate the concepts presented above, by selecting from each theme paper a few topics based on the identification of key target functions:

- that play a major role in maintaining an improved state of health and well-being and/or reduction of risk of disease;

- for which appropriate markers are available and/or feasible;

- for which potential opportunities exist for modulation by candidate food components.

\subsection{Markers - a proposal for classification}

One key, but difficult, approach to the development of functional foods is the identification and validation of relevant markers that can predict potential benefits or risks relating to a target function in the body.

If markers represent an event directly (i.e. causally) involved in the process they should be considered as factors, whereas if they represent correlated events they should be considered as indicators.

Markers relevant to functional foods (see Fig. 1) can also be classified according to whether they:

- relate to the exposure to the food component under study, such as a serum, faecal, urinary or tissue marker. For instance, the increased level of red-blood-cell folate is a marker of exposure to folate in food and the increased level of blood tryptophan is a marker of exposure to tryptophan in food. Markers relating to exposure to the functional food component can give some indication, but not absolute proof, of the bioavailability of the food component.

- relate to the target function or biological response, such as changes in body fluid levels of a metabolite, protein or enzyme (e.g. the reduction in levels of plasma homocysteine as a possible response to dietary folate, and the increased levels of brain serotonin as a possible response to dietary tryptophan).

- relate to an appropriate intermediate endpoint of an improved state of health and well-being and/or reduction of risk of disease, such as the measurement of a biological process that relates directly to the endpoint (e.g. the extent of narrowing of the carotid artery as evidence of cardiovascular disease, or functional imaging

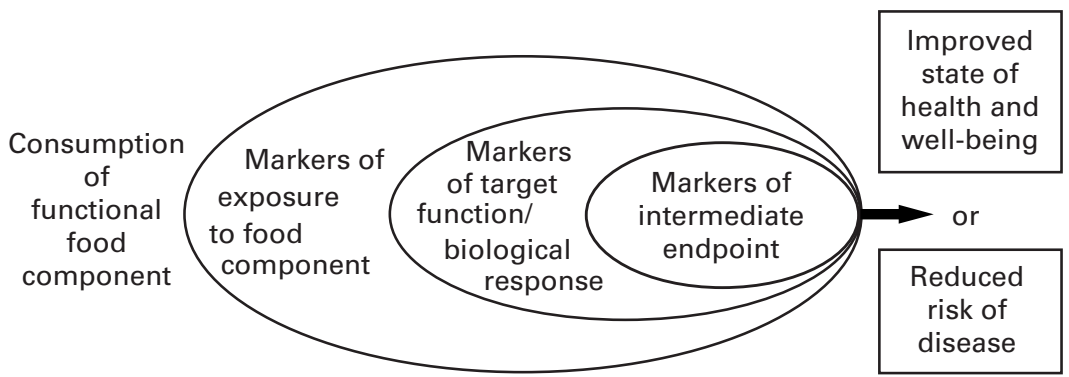

Fig. 1. Classification of markers relevant to the effects of functional foods. This is a diagrammatic representation to show how different types of markers would be expected to lie within a logical progression from the food component to the health outcome. The types of markers are completely independent of each other. Markers can be either indicators or, if they can be proven to be causal, factors (see Section 2). 
of the brain by magnetic resonance imaging as an intermediate endpoint marker for the amelioration of depression).

Markers of exposure and markers of biological response can either be factors that are causally related to the endpoint, or indicators that are indirectly related. Markers of an intermediate endpoint are likely to be factors, rather than indicators.

Markers become less specific and more attenuated and subject to confounding variables as they become more remote from the endpoint. Conversely, they become more specific and quantitatively related the closer they are to the endpoint in question. The elucidation of the mechanisms leading to health outcomes would refine the identification of markers and their appreciation.

This differential classification is considered to be of real importance in the development of new markers for use in human studies. The results from such studies can also form a scientific basis for formulating and controlling claims (see Section 5).

\subsection{Criteria for markers}

In general, all markers, whether they are biochemical, physiological or behavioural in nature, should be feasible, valid, reproducible, sensitive and specific. The following criteria should apply equally well, for example, to measurements of particular blood components as they do to measurements of subjective experience and behaviour.

- Markers should represent relatively immediate outcomes, which can be used to assess interventions in a reasonable timescale; they could, therefore, wherever possible, replace later and more remote outcomes as have been used in some epidemiological studies.

- Markers must be rigorously validated and amenable to standard quality-control procedures.

- Markers must be clearly linked to the phenomena involved in the biological process being studied. It is important to prevent the pursuit of increasingly accurate and precise measurements, which have limited biological significance.

- Markers should undergo single-centre studies to establish their sensitivity (i.e. the frequency of a negative test when the process is present) and their specificity (i.e. the frequency of a positive test when the process is absent). They must also be shown to be reproducible in different centres.

- Markers must be measurable in easily accessible material, or obtainable using methodology that must be both ethical and minimally invasive.

- Dynamic responses might be as useful as, or more useful than, static measurements. For example, changes in markers during clearance studies and in postprandial situations and studies of enzyme function, induction and suppression should be considered.

- Appropriate static and dynamic markers might also be based on objective assessments of psychological and physical performance and subjective assessments of quality of life or other similar outcomes.

These criteria for markers should be taken into account before human intervention studies are carried out. In many cases a 'battery' of markers might be needed in order to create a 'decision tree' from multiple tests. A new generation of human intervention studies using markers that accord with these criteria will generate readily interpretable, valid and reliable data, which can form the basis for future development of functional foods in the European population. Markers, arising from new techniques such as molecular biology, might be expected to identify target groups who could benefit from functional foods.

\subsection{Safety considerations}

Functional foods must be safe according to all standards of assessing food risk. However, the concept of risk versus benefit cannot be applied in such a straightforward manner as it is for drugs; new concepts and new procedures will need to be elaborated and validated.

For example, the safety evaluation of micronutrients must take into account potential adverse effects of low intakes (clinical deficiency) as well as effects from intakes that are too high (clinical toxicity). Furthermore, a more traditional toxicology testing approach might be suitable to assess the safety of (phyto)chemicals, the daily intake of which remains low, but it is not necessarily ideal for new functional food components, which might account for a relatively larger percentage of the total food intake. The classical 'dose-effect relationship' might lead to considerations of physiological/nutritional disturbances that are irrelevant to standard safety assessment. If a functional food is considered in the framework of novel foods, the decision tree leading to a relevant package of toxicity testing will be driven by the principle of substantial equivalence of the tested food compared with traditional counterparts (see Jonas et al. 1996).

Protocols for human nutrition studies need to be developed including, in some cases, post-marketing surveillance. Even though the design of clinical studies as used in drug development can serve as a reference point, specific protocols and specific criteria relevant to functional foods might be needed. It might also be necessary to identify specific target groups of individuals who might present higher/lower susceptibilities to potential adverse effects and to consider that the effects of functional foods might be positive in some target groups and negative in others. Finally, the long-term consequences of the interaction(s) between functional food components and function(s) in the body and the interactions between components must be carefully monitored. This EU Concerted Action proposes that markers as described in Sections 2.3 and 2.4 should, if possible, be used and integrated in the safety assessment.

\section{TARGET FUNCTIONS AND RESEARCH OPPORTUNITIES IN RELATION TO HEALTH OUTCOMES (see Bellisle et al. 1998, S5-S45)}

\subsection{Growth, development and differentiation}

\subsubsection{Introduction}

Food supply, and the metabolism of food components, during both pregnancy and lactation have important implications on intra-uterine and postnatal development of 
children. Early nutrition might modulate growth and development of the organism, which is thought to affect neural function and behaviour. Equally important, the effects of early nutrition also appear to influence the overall quality of life by exerting life-long programming effects on modulating health, disease and mortality risks in adulthood.

\subsubsection{Key target functions}

3.1.2.1 Maternal adaptations during pregnancy and lactation. The energy cost of development of the placenta and fetus is only about $6 \%$ of the mother's normal requirements. This value is relatively low and is probably due to adaptations during pregnancy, which enable the mother to increase the absorption and use of nutrients from her diet, and also the mother's ability to use stored nutrients for fetal growth. Some of these adaptations occur very early in pregnancy; others, such as those involving the increased absorption of iron in the gut, take place in the later stages. Some adaptations seem to target specific nutrients such as iron, towards the placenta for transfer to the fetus, but these transport processes have not been well characterized.

It is important to ensure that mothers are adequately nourished during lactation and between pregnancies with every nutrient, so as to 're-stock' any nutrient storage depots that might have been depleted during pregnancy.

3.1.2.2 Fetal development. Fetal development is under genetic control, which can be disturbed by severe deprivations or excesses of nutrients. The critical periods of fetal organ formation often occur before the fetus has a placental supply of nutrients from the mother. The best documented example of this is the spectrum of iodine deficiency disease. Poor iodine status is associated with an increased risk of miscarriage in early gestation and preterm delivery, as well as abnormal mental development of the infant. However, the mechanisms and regulation of supplying nutrients to the early embryo and their susceptibility to diet are not clear.

Another more recent example is the critical period for the effect of additional dietary intakes of folate on the optimal development of the neural tube - a very early component of the nervous system. Intervention at this critical stage can result in a reduction in incidence of a number of neural tube defects, one of which is spina bifida.

3.1.2.3 Infant and child growth and development. Postnatal growth and development of the infant is a continuation of the in utero events and processes. Although the nature and means of delivering nutrients has changed significantly, the functional and structural integrity of organs and tissues such as the gut, liver, skeleton, brain, adipose tissue, muscle, blood cells and the immune system continue to mature and remain potentially susceptible to dietary factors.

The newborn infant has an intermittent nutrient supply from breast milk or infant formula, both of which are rich in lipids. Absorption of nutrients takes place through the intestine, and delivery to the tissues is initially via the portal circulation. At the transition between suckling and weaning, there is a switch to a more solid diet with a lower fat and higher carbohydrate content.

The adaptation of infants to these changes requires important modifications of substrate and energy metabolism through the induction of metabolic pathways. The programming of metabolic responses at the cellular level, the programming of stem cells and the control of programmed cell death are not well understood. Postnatal development and differentiation also creates distinctive requirements for nutrients such as amino acids and long-chain fatty acids. Some of these, although not regarded as essential in adults, are considered to be 'conditionally' essential in the infant.

There is now epidemiological evidence that early diet, and presumably related metabolic events in utero and in infancy, manifest themselves by inappropriate intra-uterine and postnatal growth. This is now thought to predispose the child to obesity, diabetes mellitus, and risk factors for CVD in adult life. These later consequences might arise from alterations in critical stages in metabolic programming of several nutrients and might be analogous to the early consequences of deficiency of iodine and folate.

Breast milk contains some constituents derived directly from the maternal diet that might not only have an obvious role to play in determining the baby's perception of smell and taste (which is well developed in utero) but also in the development of immunotolerance. Thus it is possible that early diet might condition the development of taste preferences, which, in turn, could affect the diversification of the diet in later infancy.

\subsubsection{Examples of options for modulation}

Human breast milk is an example of a food with functional properties. The precise roles and essentiality of many of the diverse components of breast milk are not certain and further clarification of their role might be informative for the development of functional foods. Bioactive components in human milk include the specific nature of the protein and lipid composition, digestive enzymes, growth factors, peptide and steroid hormones, free amino acids (taurine, arginine, glutamine), choline, polyamines, nucleotides, nonprotein nitrogen sources such as urea, immunoglobulins and oligosaccharides.

These components in breast milk might be present adventitiously or they might be present for specific purposes, which have been developed under evolutionary pressure. In any case, study of their function can possibly inform the development of infant formulae and might have wider implications.

\subsubsection{Research opportunities}

\subsubsection{Basic science}

- The development of the interaction between food components and gene expression needs to be better elucidated. Targeting of genes affected by, and the nature of interaction with, specific nutrients such as glucose, cholesterol, fatty acids and amino acids needs to be characterized.

- To what extent is metabolic maturation intrinsically controlled? How much is it responsive and determined by external stimuli such as the pattern of feeding and changes in the nature of the diet?

- The bioactive compounds in breast milk should be characterized in further detail. There might be opportunities 
Table 1. Examples of opportunities for modulation of target functions related to growth, development and differentiation by candidate food components with possible markers*

\begin{tabular}{|c|c|c|}
\hline Target functions & Possible markers & Candidate food components \\
\hline Skeletal development & $\begin{array}{l}\text { ultrasound measures } \\
\text { anthropometric measures } \\
\text { bone mineral density (e.g. DEXA) }\end{array}$ & $\begin{array}{l}\text { calcium } \\
\text { vitamin D } \\
\text { vitamin C }\end{array}$ \\
\hline Growth and body composition & $\begin{array}{l}\text { anthropometry } \\
\text { body fat mass } \\
\text { total body water } \\
\text { procollagen propeptide excretion } \\
\text { urinary creatinine excretion }\end{array}$ & $\begin{array}{l}\text { growth factors } \\
\text { essential amino acids } \\
\text { unsaturated fatty acids }\end{array}$ \\
\hline Immune function & cellular and non-cellular immune markers & $\begin{array}{l}\text { vitamin } A \\
\text { vitamin D } \\
\text { antioxidant vitamins } \\
\mathrm{n}-3 \text { and } \mathrm{n}-6 \text { PUFA } \\
\text { trace elements } \\
\text { arginine } \\
\text { nucleotides and nucleosides } \\
\text { probiotics }\end{array}$ \\
\hline $\begin{array}{l}\text { Psychomotor and cognitive } \\
\text { development }\end{array}$ & $\begin{array}{l}\text { tests of development, behaviour, cognitive function and visual acuity } \\
\text { (electro-) physiological measurements }\end{array}$ & $\begin{array}{l}\mathrm{n}-\text { and } \mathrm{n}-6 \text { PUFA } \\
\text { iron } \\
\text { zinc } \\
\text { iodine }\end{array}$ \\
\hline
\end{tabular}
* The information given in this table is derived from the Theme Paper (see Bellisle et al. 1998, S5-S45), where, if not given in this Consensus Document, further details
of options for modulations, markers and safety issues can be found.

$n-3$ PUFA $=n-3$ series long-chain polyunsaturated fatty acids.

$n-6$ PUFA $=n-6$ series long-chain polyunsaturated fatty acids.

$D E X A=$ dual-energy $X$-ray absorptiometry.

to isolate and include them as functional components in infant formulae or other foods.

- Research is required on the interactions of different dietary components on the development and long-term function and integrity of intestinal function (substrate transporters, mucosal immunity and xenobiotic metabolizing systems), intestinal growth and microflora.

- Oral immunotolerance and dietary factors modulating the development of food protein allergy need better characterization.

\subsubsection{Cross-sectional and prospective epidemiological} evidence

- What is the interaction between the ingestion of human breast milk and the programming and development of infant metabolism during the subsequent introduction of diversified diet?

- Possible mechanisms must be identified to explain the epidemiological associations between impaired intrauterine and postnatal growth and the prevalence, in adulthood, of obesity, diabetes mellitus, hypertension, hypercholesterolaemia, cardiovascular disease, obesity and other diseases. Well-structured prospective studies, using appropriate markers, are needed.

\subsubsection{Markers}

- There is a general need to apply many of the markers developed for the study of intermediary metabolism and well-being (see later in this Section) to the prospective study of the long-term impact of feeding in early childhood.

\subsubsection{Human intervention studies}

- The nutritional and metabolic basis of the benefits of breast feeding and of human milk need better understanding. What are the maternal dietary factors that influence the composition of human milk? The early differences in substrate metabolism, body composition, the efficiency of growth and functional development between breast-fed babies and those fed infant formula might be important.

\subsubsection{Evidence of safety}

- We need the scientific basis to be more specific about nutritional needs during weaning and childhood to be able to address the potential risks of infants and children being given an adult diet too early or too late. Weaning and the adaptation to an adult diet is assumed to be a gradual process, but this has not been systematically established.

- Although all of childhood involves growth and development, the most critical periods are probably those in utero and during early infancy, as well as the growth spurts during pre-school age and during puberty. The development of functional foods for pregnant women and lactating mothers will need special consideration of the possible adverse effects of these foods on the fetus and child.

3.2 Substrate metabolism (Bellisle et al. 1998, S47-S75)

\subsubsection{Introduction}

A number of chronic diseases such as obesity, non-insulindependent diabetes mellitus (NIDDM) and osteoporosis are 
partly related to changes in total food intake, levels of physical activity and a poorly balanced diet.

The balance of the diet can determine substrate metabolism and the optimally balanced diet is usually expressed in terms of its macronutrient content. The carbohydrates are subdivided chemically into monosaccharides, disaccharides, oligosaccharides, starches, and non-starch polysaccharides, polyols and alcohol. Nutritionally, a most important distinction is between carbohydrates that are digested and absorbed in the small intestine and those that are not. The lipids are defined according to their fatty acid composition, particularly the relative contents of saturated fatty acids (SFA), monounsaturated fatty acids (MUFA) (cis and trans) and the polyunsaturated fatty acids (PUFA), which can be further sub-divided into the PUFA of the n- 6 series and the PUFA of the n-3 series.

A number of adverse metabolic changes and other cardiovascular risk factors tend to 'cluster' within individuals. These include high blood pressure, high plasma levels of insulin and/ or glucose, high plasma levels of triacylglycerols (TAG) in the fasting state and after a meal, a preponderance of small, dense low-density lipoprotein (LDL) particles and low levels of highdensity lipoprotein cholesterol (HDL). The terms 'Syndrome X', 'metabolic syndrome' or 'insulin-resistance syndrome' have been used to describe the whole cluster of cardiovascular risk factors since the underlying change appears to be an increase in insulin resistance (or a decrease in insulin sensitivity) of the tissues. The characteristic changes in the lipid profile have been called the Atherogenic Lipoprotein Phenotype (ALP). Each of these factors has been shown to relate independently to the risk of CVD, and insulin resistance is a strong marker of the risk development of NIDDM.

During physical stress such as exercise, the substrate demands are enormous and a balanced diet with a carefully planned mix of food components can play a crucial role in improving the level of performance.

\subsubsection{Key target functions}

3.2.2.1 Maintenance of appropriate body weight, body composition and body fat distribution. Obesity develops when the energy intake is consistently greater than energy expenditure. The excess energy is stored in the form of adipose tissue and results in a body weight and total body fat content that is excessive for height.

Obesity, particularly a tendency to store fat in internal, visceral depots ('central obesity'), is associated with an increased risk of developing high blood pressure, insulin resistance, diabetes and CVD. Since obesity and relative fat distribution are themselves, in part, genetically determined, there might be a considerable genetic component to the insulin resistance syndrome. Nevertheless, they must also be strongly influenced by environmental factors including diet and physical activity level. There has been a shift towards the consideration of markers that can distinguish 'central obesity' as well as the more traditional body markers for total body fat in the determination of the health risks of obesity.

3.2.2.2 Control of macronutrient oxidation. Achievement of macronutrient balance requires that the net oxidation of each macronutrient equals the amount of that nutrient in the diet. Oxidation of carbohydrates and proteins tend to vary in response to the recent intake of each fuel and thus these two fuels appear to regulate their own oxidation. In contrast, when carbohydrate content of the diet is constant, fat intake, particularly in the short term, does not always directly promote its own oxidation.

3.2.2.3 Regulation of thermogenesis. The increased energy expenditure after a meal (diet-induced thermogenesis) is mediated by a prolonged activation of the sympathetic nervous system leading to an increased catecholamine release.

3.2.2.4 Control of insulin sensitivity and blood glucose control. Insulin sensitivity is usually measured as the ability of insulin to stimulate glucose disposal, usually by means of the 'clamp' technique. The measurement of the fasting plasma insulin and glucose concentrations can be used as simple markers, suitable for large-scale epidemiological studies. Fasting blood glucose values in the upper part of the normal range, which become mildly elevated after a meal (impaired glucose tolerance), might represent a cardiovascular risk factor. Values that exceed the upper limit of the normal range might become the primary cause of the long-term microvascular complications of diabetes (such as those that affect the retina, the kidneys and the nervous system).

3.2.2.5 Control of plasma triacylglycerols. The combination of elevated plasma TAG concentrations and low HDL-cholesterol concentrations is a particularly strong risk marker for CVD. This is the characteristic disturbed lipid profile associated with insulin resistance. The magnitude and duration of elevated TAG concentrations after a meal (postprandial lipidaemia) is a strong marker of CVD risk, even in the presence of normal fasting TAG concentrations.

\subsubsection{Optimal performance during physical activity.}

Training and competition will increase the daily energy expenditure by between 500 and $1000 \mathrm{kcal}$ per hour of exercise, depending on its intensity. Large sweat losses might pose a risk to health by inducing severe dehydration, impaired blood circulation and heat transfer. This will ultimately lead to heat exhaustion and collapse. Insufficient replacement of carbohydrates might lead to low blood glucose levels, fatigue and exhaustion.

The requirements for specific nutrients and water depends on the type, intensity and duration of the physical effort. Specific nutritional measures and dietary interventions can be devised that are particularly appropriate for the distinct phases of preparation, competition and recuperation.

\subsubsection{Examples of options for modulation}

- Foods with reduced energy and/or fat content can help to control body weight and to improve glucose tolerance and insulin sensitivity. Further developments will include the use of new fat replacers and fat substitutes and the search for food components that can specifically modulate 'central obesity'. Saturated fatty acids could impair insulin sensitivity thus increasing the risk of developing 
Table 2. Examples of opportunities for modulation of target functions related to substrate metabolism by candidate food components with possible markers*

\begin{tabular}{|c|c|c|}
\hline Target functions & Possible markers & Candidate food components \\
\hline $\begin{array}{l}\text { Control of blood glucose levels } \\
\text { and insulin sensitivity }\end{array}$ & $\begin{array}{l}\text { fasting glucose } \\
\text { postprandial glucose } \\
\text { glucose tolerance test } \\
\text { glycosylated haemoglobin } \\
\text { measures of insulin dynamics } \\
\text { fasting plasma insulin }\end{array}$ & $\begin{array}{l}\text { as for body weight control, plus: } \\
\text { food with low glycaemic index } \\
\text { soluble viscous fibre } \\
\text { saturated fatty acids }(\downarrow)\end{array}$ \\
\hline Control of TAG metabolism & $\begin{array}{l}\text { fasting plasma TAG } \\
\text { postprandial plasma TAG }\end{array}$ & $\begin{array}{l}\text { as for body weight control, plus: } \\
\text { n-3 PUFA } \\
\text { n-6 PUFA } \\
\text { monounsaturated fatty acids }\end{array}$ \\
\hline Fluid homeostasis & $\begin{array}{l}\text { water balance } \\
\text { electrolyte balance }\end{array}$ & $\begin{array}{l}\text { isotonic carbohydrates } \\
\text { electrolyte fluids }\end{array}$ \\
\hline
\end{tabular}

\footnotetext{
* The information given in this table is derived from the Theme Paper (see Bellisle et al. 1998, S47-S75), where, if not given in this Consensus Document, further details of options for modulations, markers and safety issues can be found. $(\downarrow)=$ reduced intake of candidate food component.

TAG $=$ triacylglycerol

$n-3$ PUFA $=n-3$ series long-chain polyunsaturated fatty acids.

$n-6$ PUFA $=n-6$ series long-chain polyunsaturated fatty acids.
}

NIDDM. In contrast, n-6 PUFA (but not n-3 PUFA) might decrease this risk, but this needs to be confirmed by intervention trials.

- The glycaemic index (GI) can be used to categorize foods and is defined as the incremental blood glucose area after the test product has been ingested. It is expressed as a percentage of the corresponding area after ingesting a glucose load or a carbohydrate equivalent amount of white bread - both of which have high GIs. An increase in foods with a lower GI in the diet, such as pasta or legumes, might improve postprandial blood glucose levels and might help to improve insulin sensitivity in those prediposed to NIDDM.

- Non-digestible, fermentable carbohydrates in the diet (resistant starch, non-starch polysaccharides and oligosaccharides and polyols), and, possibly, some of their fermentation products, could also lower blood glucose levels by a decrease in liver glucose production. Cell wall polysaccharides are able to 'encapsulate' dietary carbohydrates and, in so doing, slow their accessibility and thus their digestibility. Soluble viscous fibres consumed in large amounts have the most effect on postprandial glucose and insulin response. The effect is related to viscosity, which inhibits mixing and diffusion in the intestinal tract and possibly delays gastric emptying.

- Caffeine is a potent thermogenic agent of the group of methylxanthines, but other pungent components from spices, such as ginger, chilli and mustard, are also potential thermogenic agents.

\subsubsection{Research opportunities}

\subsubsection{Basic science}

- Further research is necessary to understand mechanisms responsible for insulin resistance, in particular in relation to the role of intermediary carbohydrate and fat metabolism in the development of 'central' obesity.

- What is the effect of different types of carbohydrate in the regulation of carbohydrate balance? What are the mechanisms behind the impact of the ratio of PUFA to SFA in the diet on fat oxidation? We need to know the impact of the different short-chain fatty acids (SCFA), such as acetic and propionic acids, on metabolism in general.

- Are there mechanisms, apart from the activation of the sympathetic nervous system, that can account for the elevation of diet-induced thermogenesis?

- Nutrient mechanisms that have an impact on genetic expression or immunological function should be examined. Modern methods of molecular biology and immunology must be used with a focus on post-translational modifications related to various proteins, diets or indispensable substrates. Interactions between different nutrients are an essential focus of future studies because of alterations caused by the ageing process.

\subsubsection{Cross-sectional and prospective epidemiological} evidence

- Is it possible to make a distinction between the genetic and the environmental components of the ALP? ALP appears to be a secondary consequence of insulin resistance 
but is often regarded as a genetic condition. How prevalent is ALP in non-obese, non-diabetic subjects?

- Is it reasonable to base our understanding of the effects of dietary manipulation within individuals on evidence from epidemiological studies? An elevated plasma TAG concentration, for example, might be a risk factor for CHD in epidemiological terms, but does it then follow that elevation of plasma TAG by dietary means confers an equivalent risk?

\subsubsection{Markers}

- Achievement of the above goals requires the development of analytical methods (bioassay), the identification of markers and a more precise knowledge of nutrient requirements.

\subsubsection{Human intervention studies}

- What are the long-term effects of macronutrient replacers, in particular fat replacers, on energy and fat balance and on body weight control? Is the consumption of fatreduced or energy-reduced foods eventually compensated for by an increased total food intake?

- Long-term intervention studies are required to investigate whether insulin resistance can be ameliorated by the manipulation of the carbohydrate: fat ratio in the diet and by the composition of the dietary fatty acids. Shorterterm mechanistic studies should also be carried out within these long-term studies to investigate the regulation and rate of adaptation of carbohydrate and fat balance within the body. Potential gene/nutrient interactions must be considered.

- Low GI foods are a useful tool for dietary management of people with NIDDM, and some can help to reduce plasma cholesterol concentrations and insulin resistance. Their further potential should be explored, particularly in relation to the prevention of NIDDM and cardiovascular diseases.

- It is critically important that long-term (at least 6 months) studies of the effects of low-fat, high-carbohydrate diets on plasma lipid constituents are carried out. Is the elevation of plasma TAG concentration on a highcarbohydrate diet transient or longer lasting? What is the nature of the elevation of plasma TAG concentrations, i.e. what are the size and density of lipoprotein particles containing TAG? What is the impact of the elevation of TAG on other lipid constituents (e.g. the density distribution of LDL particles) and on postprandial lipidaemia?

- It is important to know the effects of different types of fatty acids and available carbohydrates, as well as the effects of the carbohydrate : fat ratio, on long-term energy and substrate balance.

\subsubsection{Evidence of safety}

- The safety of substances that modulate energy and glucose metabolism should be evaluated in short- and long-term studies because of the risk of disturbances in the lipid and glucose metabolism.

\subsection{Defence against reactive oxidative species (Bellisle et al. 1998, S77-S112)}

\subsubsection{Introduction}

The normal development and functioning of any aerobic organism is associated with the generation of reactive oxidative species (ROS), referred to as oxidants or prooxidants. ROS are responsible for oxidative damage to biological macromolecules such as DNA, lipids or proteins, which might be involved in the initiation or progression of diseases, such as some forms of cancer and cataract, cardiovascular disease, age-related macular degeneration, rheumatoid arthritis and a number of neurodegenerative conditions such as Parkinson's disease or Alzheimer's disease. Gene regulation and the immune system might also be affected. It is also possible that ROS are involved in intracellular signal transduction.

ROS can arise endogenously as secondary products from normal metabolic reactions, or they can be primarily formed as part of the body's defence against foreign organisms. The body is also exposed to ROS from external sources; many prooxidants are present in the diet and are inhaled in cigarette smoke and in other forms of air pollution. The most relevant ROS are peroxyl radicals (ROO-), the nitric oxide radical (NO), the superoxide anion radical (O2--), the hydroxyl radical $(\mathrm{OH} \cdot)$, singlet oxygen $\left({ }^{1} \mathrm{O}_{2}\right)$, peroxynitrite (ONOO-), and hydrogen peroxide $\left(\mathrm{H}_{2} \mathrm{O}_{2}\right)$.

To counteract the oxidant load, a diversity of defence mechanisms operate in biological systems, which include both enzymic and non-enzymic antioxidant systems. An antioxidant has been defined as 'any substance that, when present in low concentrations compared to that of an oxidizable substrate, significantly delays or inhibits the oxidation of that substrate'.

\subsubsection{Key target functions}

3.3.2.1 Preservation of structural and functional activity of $D N A$. Oxidative damage to DNA can lead to strand breaks and/or the modification of DNA bases, which might result in point mutations, deletions, or gene amplification. The COMET assay can measure distortion of morphology due to damaged DNA. High-performance liquid chromatography (HPLC) and gas chromatography-mass spectrophotometry (GC-MS) methods can be used to measure damaged DNA bases such as 8-hydroxy-deoxyguanine; antibody techniques are currently also being developed for this purpose. However, measurement of gross damage to DNA might give little information about oxidative damage to specific genes whose expression has a key cellular function.

3.3.2.2 Preservation of structural and functional activity of circulating lipoproteins and of polyunsaturated fatty acids in cell membranes. Oxidation of the PUFAs in LDL within the arterial wall plays a major role in the pathogenesis of fatty streak formation in arteries, which, in turn, leads to atherosclerosis. Oxidative modification of both the lipid and protein part of the lipoprotein contribute to the atherogenic properties of oxidized $\mathrm{LDL}\left(\mathrm{LDL}_{\mathrm{OX}}\right)$. The products of lipid oxidation are best measured in plasma as lipid hydroperoxides or their derivatives such as malondialdehyde, or as isoprostanes. Development of isoprostane measurement will advance specificity and precision and is expected to provide a marker for whole body lipid peroxidation. Direct measurements of oxidized LDL are also now possible. 
Table 3. Examples of opportunities for modulation of target function by candidate food components and possible markers related to defence against reactive oxidative species $^{*}$

\begin{tabular}{|c|c|c|}
\hline Target functions & Possible markers & Candidate food components \\
\hline $\begin{array}{l}\text { Preservation of structural and functional } \\
\text { activity of polyunsaturated fatty acids }\end{array}$ & $\begin{array}{l}\text { measurement of lipid hydroperoxides or } \\
\text { derivatives }\end{array}$ & $\begin{array}{l}\text { vitamin } \mathrm{E} \\
\text { vitamin } \mathrm{C} \\
\text { carotenoids } \\
\text { polyphenols including flavonoids }\end{array}$ \\
\hline $\begin{array}{l}\text { Preservation of structural and functional } \\
\text { activity of proteins }\end{array}$ & measurement of damaged proteins or components & $\begin{array}{l}\text { vitamin } \mathrm{E} \\
\text { vitamin } \mathrm{C} \\
\text { selenium } \\
\text { carotenoids } \\
\text { polyphenols including flavonoids }\end{array}$ \\
\hline
\end{tabular}

* The information given in this table is derived from the Theme Paper (see Bellisle et al. 1998, S77-S112), where, if not given in this Consensus Document, further details of options for modulations, markers and safety issues can be found.

Oxidative stress might play a role in the development of neuronal degeneration, since ROS can cause peroxidation of the PUFA in all cell membranes including nerve cells with subsequent membrane disruption.

3.3.2.3 Preservation of structural and functional activity of proteins. Proteins in the lens of the eye are extremely long-lived and often show oxidative damage by ROS through chronic exposure to light and oxygen. Damaged proteins can aggregate and precipitate, giving rise to cataracts and to macular degeneration in elderly people. The methodology for the measurement of oxidative damage to the protein part of lipoproteins and other proteins has not, as yet, been sufficiently developed and evaluated.

\subsubsection{Examples of options for modulation}

- The human diet contains an array of different compounds that possess either antioxidant activities or the apparent ability to scavenge ROS. Epidemiological studies support the hypothesis that the major antioxidant nutrients vitamin $\mathrm{E}$ and vitamin $\mathrm{C}$ (as well as $\beta$-carotene, which might or might not be acting as an antioxidant in vivo) play a beneficial role in the maintenance of health and in the reduction of chronic disorders. LDL oxidation is efficiently inhibited by lipophilic antioxidants, of which $\alpha$-tocopherol is the most important in in vitro systems; $\beta$-carotene is, however, ineffective. Carotenoids and polyphenolic compounds such as flavonoids are also potent antioxidants in other in vitro systems, but there is no evidence that they function this way in vivo. Vitamin $\mathrm{C}$ has been demonstrated to be the most important antioxidant in the human eye.

- The food industry has a long experience in the control of oxidative damage in foods and this expertise can be used to advantage for the protection of antioxidants specifically used as food components to be beneficial to health.

\subsubsection{Research opportunities}

3.3.4.1 Basic science

- More studies are needed on the uptake, distribution, metabolism and elimination of vitamin $\mathrm{E}$ and vitamin $\mathrm{C}$.

- Can flavonoids and carotenoids be taken up by human subjects and distributed to the tissues in quantities sufficient to confer a biological effect, and what is the nature of that effect if it occurs?

- Are there combined effects of synergy or antagonism both with respect to the antioxidants themselves or to other food components?

- Is it the antioxidant role of the substance that is important, or is it some other function, such as some aspects of the modulation of gene expression?

- Further work is needed on the chemical analysis of the antioxidant content of foods so that more realistic food composition tables can be compiled. Ideally this should take account of agricultural practices, industrial processing and food preparation.

3.3.4.2 Cross-sectional and prospective epidemiological evidence

- Better food composition data and better markers of disease could enable re-analysis of existing epidemiological data in some cases and will improve study design in further investigations. Further knowledge of basic science will also allow consideration of confounding influences in epidemiological studies.

\subsubsection{Markers}

- Because direct measurement in vivo of the prooxidants that are detrimental to human health is difficult or impossible, it is essential to develop and validate a number of markers of oxidative damage to key body structures that are non-invasive and can be used ethically and acceptably in human volunteers.

- Existing methods for measurement of oxidative damage in human subjects in a non-invasive manner must be 
refined and validated. Results obtained in the same laboratory on identical material using different, but complementary, methodology should be compared. For the purposes of quality assurance, results from several different participating laboratories of oxidative damage in identical samples must be compared.

- In the case of reduction of disease risk, it is important to show that markers are clearly linked to those phenomena that give rise to a specific human disease since its development is the ultimate paradigm by which the relevance of a marker is judged. For example, which of the multiple oxidative modifications of DNA are those that lead to carcinogenesis? What is the comparative relevance of modification of the protein and lipid in LDL particles or of changes in thickening of the carotid artery wall, all of which contribute to the process of atherogenesis?

\subsubsection{Human intervention studies}

- A new generation of intervention trials using validated and accepted markers as intermediate endpoints might be used to test the efficacy of antioxidants; these will provide results in a shorter time than old-style intervention studies where development of disease was the only marker. Bioavailability studies and dose-response studies, in combination with the development and application of biomarkers, are required for a successful research strategy.

- These new studies will enable quantitation of the optimal levels of intake of antioxidants. Care must be taken to ensure that the importance of the antioxidant contribution of the whole diet, as distinct from that of each individual antioxidant, is evaluated.

\subsubsection{Evidence of safety}

- The mechanism for the apparent exacerbation of the incidence of lung cancer in heavy smokers given supplements of $\beta$-carotene needs urgent clarification. Further work is also needed on the safety of other carotenoids, flavonoids and other phenolic compounds that have been shown to have bioactivity in human subjects.

- Developments in food technology will include the preservation, enhancement, and perhaps addition de novo to foods, of the particular forms of antioxidants that have been shown to have functional capacity.

\subsection{Cardiovascular system (Bellisle et al. 1998,} S113-S146)

\subsubsection{Introduction}

CVD is essentially caused by the narrowing of the arteries, which can lead to a reduced supply of oxygen to organs such as the heart, skeletal muscle, brain, intestine and kidneys. Key elements involve changes in the constituents of the blood and in the walls of the blood vessels. The main target functions in this process are those involved with the integrity of the blood vessels (e.g. control of cellular immunology and hypertension); in lipoprotein homeostasis (e.g. insulin resistance) and the control of the thrombogenic balance (the likelihood of blood clot formation). The interdependence of these factors has not been fully characterized, and since only $50 \%$ of the incidence of CVD can be explained by the known risk factors, there are possibly other unexplored contributory and interactive factors, such as genetic polymorphisms.

\subsubsection{Key target functions}

3.4.2.1 Lipoprotein homeostasis. A raised plasma concentration of LDL cholesterol is a risk factor for CVD. High levels of lipoprotein(a), very low-density lipoprotein (VLDL), TAG concentrations and low levels of HDL cholesterol are strong risk indicators, rather than risk factors, for CVD.

It is important to consider the lipoprotein profile after a meal (the postprandial response), as well as under fasting conditions, in relation to CVD. For example, the atherogenicity of lipoprotein remnants is more pronounced on high-fat diets, which induce higher postprandial TAG levels, even if fasting TAG levels are low. Long-chain n-3 PUFA from fish oil might reduce the postprandial TAG response.

The efficacy of dietary manipulations to alter lipoprotein profiles depends on an individual's genetic constitution. For example, there is a genetic polymorphism for one of the apolipoproteins, apolipoprotein E (apoE). People with the apoE2 isoform have a delayed clearance of lipid-rich particles after a meal that is rich in fat, because this type of apolipoprotein has a lower affinity for the receptors on liver cells, resulting in slower removal from the plasma.

3.4.2.2 Endothelial and arterial integrity. Damage to, or activation of, the endothelial cells that line the arteries, as well as more general structural damage at susceptible points in the arteries (such as bifurcations), might increase the risk of atheromatous plaque formation. Endothelial activation increases production, release or exposure of various reactive molecules such as cytokines, adhesion molecules and markers of platelet activation and it causes decreased synthesis of some prostaglandins and transforming growth factors. The consequences might be inflammatory changes and fibrosis of the vascular wall with an increased risk of small blood clot formation. These consequences are all thought to be involved in fibrous plaque formation.

3.4.2.3 Control of thrombogenic potential. The control of thrombogenic potential is likely to be an important element in the reduction of CVD. However, available measures of platelet function in vitro and plasma concentration of factors involved in coagulation and in fibrinolysis are not reliable indicators of any pro-thrombotic state or risk in humans. Similarly, the particular influence of endothelial cells on this process, as indicated by relevant markers, has not been sufficiently elucidated.

3.4.2.4 Control of homocysteine levels. Epidemiological data suggest that high plasma levels of homocysteine are associated with increased risk of CVD and several proposed mechanisms for the effects of homocysteine on atherogenesis and thrombosis have been suggested.

3.4.2.5 Control of hypertension. CVD is directly related to systolic and diastolic blood pressure, and antihypertensive measures reduce the risk of coronary disease. Evidence suggests that, in addition to certain food components (e.g. sodium, calcium, certain fatty acids), many other factors 
Table 4. Examples of opportunities for modulation of target functions related to the cardiovascular system by candidate food components with possible markers*

\begin{tabular}{|c|c|c|}
\hline Target functions & Possible markers & Candidate food components \\
\hline Lipoprotein homeostasis & $\begin{array}{l}\text { lipoprotein profile, including: } \\
\text { plasma LDL-cholesterol } \\
\text { plasma HDL-cholesterol } \\
\text { plasma TAG (fasting and postprandial response) } \\
\text { lipoprotein particle size }\end{array}$ & $\begin{array}{l}\text { \#SFA }(\downarrow) \\
\text { MUFA } \\
\text { PUFA } \\
\text { certain phytosterols } \\
\text { certain phytostanols } \\
\text { soluble fibre } \\
\text { trans-fatty acids }(\downarrow) \\
\text { soy proteins } \\
\text { tocotrienols } \\
\text { fat replacers }\end{array}$ \\
\hline Arterial integrity & $\begin{array}{l}\text { \#growth factors } \\
\text { adhesion molecules } \\
\text { cytokines }\end{array}$ & $\begin{array}{l}\text { certain antioxidants } \\
\text { n-3 PUFA from fish }\end{array}$ \\
\hline Control of thrombogenic potential & $\begin{array}{l}\text { platelet function } \\
\text { activated clotting factors and activation peptides }\end{array}$ & $\begin{array}{l}\text { n-PUFA from fish } \\
\text { certain antioxidants } \\
\text { linoleic acid }\end{array}$ \\
\hline Control of hypertension & systolic and diastolic blood pressure & $\begin{array}{l}\text { total energy }(\downarrow) \\
\text { sodium chloride }(\downarrow) \\
\text { n-3 PUFA from fish }\end{array}$ \\
\hline Control of homocysteine levels & plasma homocysteine levels & $\begin{array}{l}\text { folic acid } \\
\text { vitamin B6 } \\
\text { vitamin B12 }\end{array}$ \\
\hline
\end{tabular}

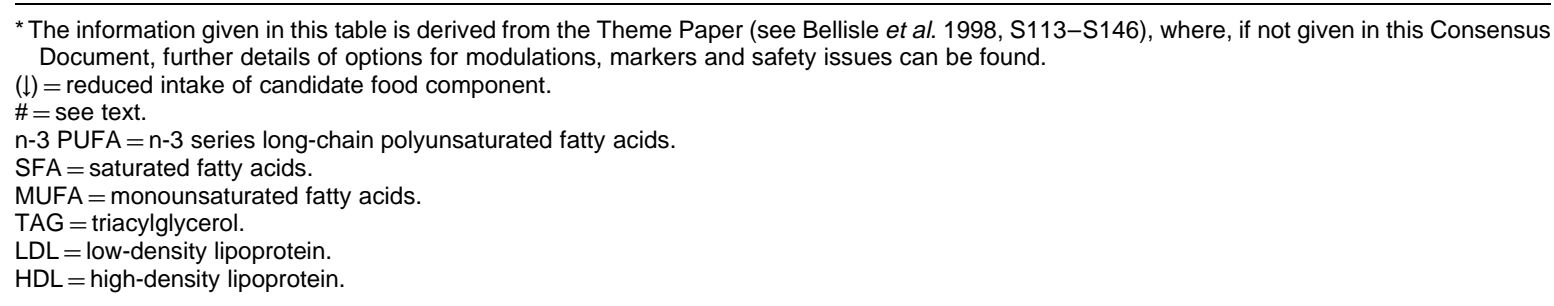

are involved in the aetiology of hypertension (e.g. genetic predisposition, obesity, etc.).

\subsubsection{Examples of options for modulation}

- Dietary SFA (chain length up to 16 carbon atoms) increase plasma LDL cholesterol concentrations more than they increase plasma HDL concentrations. Stearic acid (C18:0) has less effect on plasma LDL and HDL. Dietary trans-unsaturated fatty acids increase plasma LDL and reduce HDL cholesterol concentrations. Moreover, they increase the plasma lipoprotein(a) concentration. Foods low in SFA and trans fatty acids could, therefore, reduce the risk of CVD.

- The cis-unsaturated fatty acids oleic, linoleic and alpha linolenic acids reduce plasma concentrations of LDL cholesterol without significantly affecting plasma HDL cholesterol and lipoprotein(a) concentrations. Foods enriched in these unsaturated fatty acids, therefore, could also be used to reduce the risk of CVD.

- Soluble fibre, certain phytosterols and phytostanols and other food components can reduce LDL cholesterol concentrations, particularly in hyperlipidaemic subjects. Similar effects have been shown for ethanol and for garlic.

- The long-chain n-3 PUFA found in fish oils can promote mechanisms that improve endothelial and arterial integrity, particularly those dependent on the balance of prostaglandins. They also reduce plasma TAG and may also have suppressive effects on the cellular immune system.
- Diets rich in antioxidants can influence the activities of immune-competent cells and can inhibit the expression of genes coding for the cell-cell adhesion factors.

- There is scope for the modulation of factors such as high plasma homocysteine concentrations and high blood pressure to protect vascular integrity.

\subsubsection{Research opportunities}

\subsubsection{Basic science}

- Modifications to certain fatty acids, cholesterol and other lipids should be developed in order to influence their absorption and/or systemic handling.

- What is the mechanism of LDL uptake by monocytes and macrophages and what are the factors influencing the access of these cells to the vascular sub-endothelial space?

- The underlying short- and long-term mechanisms, fastcell signalling-pathway factors involved in cell-cell interactions, thrombogenic and inflammatory reactions should be studied in detail at the level of gene activation and transcription. These could help to explain the links between certain food components and the development and possible regression of vascular lesions.

3.4.4.2 Cross-sectional and prospective epidemiological evidence

- Because cardiovascular disease is a multifactorial condition, we need to know, in the context of nutrition and 
public health policy, who is likely to benefit from particular dietary/ingredient modifications.

- There is also a need to characterize prospectively, and establish relationships between, population groups and possible risk indicators/factors, such as high blood pressure, high levels of homocysteine in the blood, abnormal lipid profiles, and CVD.

\subsubsection{Markers}

- Prospective validation studies should be performed to establish to what extent the presently available indicators actually reflect the risk of arterial thrombosis. The current available indicators of arterial thrombosis tendency include platelet aggregation in vitro, urinary excretion of thromboxane- and prostacyclin metabolites and of specific platelet proteins, plasma concentrations of soluble forms of cell adhesion molecules, activation fragments of clotting factors, and fibrin degradation products.

- It might be necessary to develop and validate new methods to measure in vivo arterial thrombosis tendency in humans and to look for, and prospectively validate, more specific in vivo activation markers for platelets, endothelial cells, leukocytes, clotting factors and the fibrinolytic process.

- Markers of cellular and immune activation are needed. Measurements of soluble adhesion molecules in plasma and, possibly, of cleavage products in urine, might improve the diagnosis of CVD and the evaluation of its prognosis. In addition these markers may help to establish and monitor the impact of nutrient supplementation.

\subsubsection{Human intervention studies}

- Interactions and relative amounts of fatty acids (e.g. the n-3 PUFA : n-6 PUFA ratio, palmitate) and the effect of dietary cholesterol on lipid metabolism (particularly on postprandial hyperlipidaemia), should be studied in wellcontrolled dietary trials. These investigations should examine systemic trafficking of the fatty acids and the lipoproteins. Effects on other lipid parameters, such as the key enzyme activities in TAG metabolism and lipoprotein particle sizes, should also be studied in order to understand the dietary effects on lipoprotein metabolism.

- The effect of selected dietary components (e.g. individual n-3 and n-6 fatty acids and combinations of them, antioxidants, fibre) on the processes involved in arterial thrombus formation should also be established and characterized.

- The effect of dietary constituents, e.g. fatty acids and bioactive amines, on nitric oxide (NO) metabolism, free radicals and other local endothelial mediators of vascular tone should be explored.

- Particular attention ought to be paid to study design and to characterization of experimental subjects. Genetic polymorphisms and diet-gene interactions, life-style effects and endocrine factors must all be considered.

\subsubsection{Evidence of safety}

- The potential toxicity of very high intakes of long-chain PUFA and antioxidants should be investigated.
3.5 Intestinal physiology (Bellisle et al. 1998, S147-S170)

\subsubsection{Introduction}

The gut is an obvious target for the development of functional foods since it acts as an interface between the diet and the events that sustain life. The target functions relating to the physiology of the gut can be subdivided according to those that determine transit time and stool characteristics, those that involve the colonic microflora, those that are associated with the gut-associated lymphoid tissue (GALT), and those that depend on the products of nutrient fermentation.

The development of intestinal and mucosal microflora provides the basis for the gut barrier that prevents pathogenic bacteria from invading the gastrointestinal tract. The balance of intestinal microflora together with the gut immune system allows the resident bacteria to have a protective function.

The principal role of the intestinal flora, apart from their barrier function against infection, is to salvage energy from carbohydrates not digested in the upper gut, through fermentation. The main substrates for fermentation are endogenous (e.g. mucus) and dietary carbohydrates that have escaped digestion in the upper gastrointestinal tract. These include starch that enters the colon (resistant starch), as well as non-starch polysaccharides, e.g. celluloses, hemicelluloses, pectins and gums. Other carbohydrate sources available for fermentation include non-digestible oligosaccharides, and sugar alcohols. In addition, proteins and amino acids can be effective as growth substrates for colonic bacteria. Total substrate availability in the human adult colon is $20-60 \mathrm{~g}$ of carbohydrate and $5-20 \mathrm{~g}$ of protein per day.

\subsubsection{Key target functions}

3.5.2.1 Optimal intestinal function and stool formation. Both large bowel integrity and the colonic microflora are important in determining the characteristics of the stool. Such characteristics include stool weight and consistency, stool frequency and total intestinal transit time. These are possibly the most reliable markers of general colonic function.

3.5.2.2 Colonic flora composition. Bacterial numbers and composition vary considerably along the human gastrointestinal tract but the large intestine is by far the most intensively populated microbial ecosystem with several hundred species accounting for a total of between $10^{11}-10^{12}$ bacteria per gram of contents. Quantitatively, the most important genera of intestinal bacteria in man are the bacteroides and the bifidobacteria, which can account for $35 \%$ and $25 \%$ of the known species, respectively. The microflora of the large intestine is acquired at birth and reflects the breast-milk-based diet of infants. Subsequently, however, differences in the species composition develop, largely as a result of differences in adult-type diets.

The colonic microflora is a complex interactive community of organisms and its functions are a consequence of the combined activities of the microbial components. The group of potentially health-promoting bacteria are thought to include principally the bifidobacteria and lactobacilli. The 
major diseases in which changes in the composition of the gastrointestinal microflora might possibly play a role are gastrointestinal infections, constipation, irritable bowel syndrome, inflammatory bowel diseases and colorectal cancer.

The composition and activities of the colonic microflora have to be considered both as a risk indicator and a risk factor for large bowel functions (see Section 2). The composition and activity of the faecal flora, when analysed correctly, are also good indicators of the residual colonic flora. Traditional gut microbiological methodologies are based on morphological and biochemical properties of the organisms. However, recent advances in molecular genetics for quantitative and qualitative monitoring of the nucleic acids of human colonic microflora have revolutionized their characterization and their identification. This approach also allows extensive (including multiple centre) bacteriological investigations.

3.5.2.3 Control of gut-associated lymphoid tissue (GALT) function. The human intestine GALT represents the largest mass of lymphoid tissue in the body, and about $60 \%$ of the total immunoglobulin produced daily is secreted into the gastrointestinal tract. The colonic microflora is the major antigenic stimulus for specific immune responses at local and systemic levels. Abnormal intestinal response to a foreign antigen, as well as local immunoinflammatory reactions, might, as a secondary event, induce impairment of the intestine's function because of breakdown of the intestinal barrier.

3.5.2.4 Control of fermentation products. The importance of fermentation products in the form of SCFA (namely butyrate, acetate and propionate) for colonic health has been increasingly documented. Butyrate is the most interesting of the SCFA since, in addition to its trophic effect on the mucosa, it is an important energy source for the colonic epithelium and regulates cell growth and differentiation.

\subsubsection{Examples of options for modulation}

- Probiotics, prebiotics and possibly synbiotics are interesting concepts to support the development of functional foods that are targeted towards gut functions. A probiotic is defined as 'A live microbial food ingredient that is beneficial to health'. Prebiotics, in contrast, are 'nondigestible food components that beneficially affect the host by selectively stimulating the growth and/or activity of one or a limited number of bacteria in the colon, that have the potential to improve host health'. Synbiotics are best described as 'a mixture of probiotics and prebiotics that beneficially affects the host by improving the survival and implantation of live microbial dietary supplements in the gastrointestinal tract'.

- Probiotics have been shown to stimulate the activity of some compounds of the GALT, e.g. immunoglobulin A $(\operatorname{Ig} \mathrm{A})$ antibody response, production of cytokines and reduction of the risk of rotavirus infections.

- Prebiotics (as well as probiotics) help the colonic microflora to reach/maintain a composition in which bifidobacteria and/or lactobacilli become predominant in number. This is considered optimal for health promotion.

- Non-digestible carbohydrates increase faecal mass both directly by increasing non-fermented material and/or indirectly by increasing bacterial biomass; they also improve stool consistency and stool frequency.

- Promising food components for functional foods will be those, such as specific non-digestible carbohydrates, that can provide optimal amounts and proportions of fermentation products at relevant sites in the colon, particularly the distal colon, if they are to help reduce the risk of colon cancer.

\subsubsection{Research opportunities}

\subsubsection{Basic science}

- More methods need to be developed to characterize intestinal microflora, including the non-culturable species. Molecular approaches based on the separation and identification of genetic material, such as $16 \mathrm{~S}$ ribosomal RNA, are promising.

- We need to understand the role of the human diet in the general modulation of immune functions, particularly the exact role of GALT.

Table 5. Examples of opportunities for modulation of target functions related to intestinal physiology by candidate food components with possible markers*

\begin{tabular}{|c|c|c|}
\hline Target functions & Possible markers & Candidate food components \\
\hline $\begin{array}{l}\text { Optimal intestinal function } \\
\text { and stool formation }\end{array}$ & $\begin{array}{l}\text { stool consistency } \\
\text { stool weight } \\
\text { stool frequency } \\
\text { transit time }\end{array}$ & $\begin{array}{l}\text { non-digestible carbohydrates } \\
\text { probiotics } \\
\text { prebiotics } \\
\text { synbiotics }\end{array}$ \\
\hline Colonic flora composition & $\begin{array}{l}\text { composition } \\
\text { enzyme/metabolic activities }\end{array}$ & $\begin{array}{l}\text { probiotics } \\
\text { prebiotics } \\
\text { synbiotics }\end{array}$ \\
\hline Control of GALT function & $\begin{array}{l}\lg A \text { secretion } \\
\text { cytokines }\end{array}$ & $\begin{array}{l}\text { probiotics } \\
\text { prebiotics } \\
\text { synbiotics }\end{array}$ \\
\hline $\begin{array}{l}\text { Control of fermentation } \\
\text { products }\end{array}$ & short-chain fatty acids & $\begin{array}{l}\text { prebiotics } \\
\text { synbiotics }\end{array}$ \\
\hline
\end{tabular}

* The information given in this table is derived from the Theme Paper (see Bellisle et al. 1998, S147-S171), where, if not given in this Consensus Document, further details of options for modulations, markers and safety issues can be found.

GALT = gut-associated lyphoid tissue.

$\lg \mathrm{A}=$ immunoglobin $\mathrm{A}$ 
3.5.4.2 Cross-sectional and prospective epidemiological evidence

- Further work is needed to characterize the composition and activities of human colonic microflora to investigate the effects of age and race, and to explore the influence of different dietary habits. Of particular interest would be large-scale studies of different European populations, using molecular approaches.

\subsubsection{Markers}

- Markers related to immune functions associated specifically with GALT need to be developed and validated.

- Improved characterization and validation are needed of the composition of bacterial genera and strains and the activities of the colonic microflora (e.g. specific enzymes, carcinogen formation). Only then can these be regarded as markers of important target functions.

- Early markers of carcinogenesis (e.g. recurrence of large adenomas or gut mucosal changes such as DNA damage, DNA repair and apoptosis) need to be validated as a prerequisite to investigating the effect of functional foods on the risk of colon cancer.

\subsubsection{Human intervention studies}

- What factors determine the intra-individual variation in response to probiotics and prebiotics?

- Well-designed placebo controlled human studies are required to examine the effects of different probiotic and prebiotic components.

\subsubsection{Evidence of safety}

- The long-term effects of permanent changes in the composition of the colonic microflora need to be monitored.

\subsection{Behavioural and psychological functions (Bellisle et al. 1998, S173-S193)}

\subsubsection{Introduction}

Functional foods might lead to an improved state of health and well-being and/or reduction of risk of disease. However, there are some foods or food components that are not directly related to disease or to health in the traditional sense but, nevertheless, provide an important function in terms of changing mood or mental state. These foods, therefore, are involved in creating more a sense of 'feeling well' than of 'being well'. Effects on behaviour, on emotional state, and on cognitive performance fall within this category.

Behaviour is probably the most varied and complex of all human responses. The complexity and variability arises from the fact that behaviour is the cumulative outcome of two distinct influences - biological factors (encompassing genetics, gender, age, body mass, etc.) and socio-cultural aspects (including tradition, education, religion, economic status).

\subsubsection{Key target functions}

The effects of foods on behavioural and psychological functions are conspicuously varied, typically subtle and frequently interdependent. For the purpose of simplicity, however, they can be grouped into four areas of target functions.
3.6.2.1 Appetite, satiation and satiety. Food intake can be affected by sensory, gastrointestinal and metabolic factors, as well as by social cues, all of which influence appetite, either in terms of meal size (satiation) or eating frequency (satiety) or in changes in food preferences and dietary selection.

The most widely used markers for assessing parameters of appetite and satiety are visual analogue scales. These are subjective measurements of sensations such as hunger, desire to eat and fullness.

Objective assessment of energy and/or nutrient intake of individuals is made either directly, by duplicate meal analyses, or indirectly, with diaries of dietary consumption.

Modulation of food intake is most often considered in terms of reducing food intake (to normalize body weight of overweight and obese individuals), but it is also important to consider it in terms of increasing food intake to increase body weight in persons at risk of malnutrition (such as elderly people, people suffering from eating disorders or those recovering from illness). See Section 3 for consideration of markers for body weight control.

3.6.2.2 Cognitive performance. There are several performance markers that are used to assess cognitive function. These range from reactions to single stimulus tests to those involving complex interactive inputs. They can be based on recognition of either numbers (to test vigilance, rapid information processing and/or continuous performance) or words (to monitor immediate recall, word recognition and/ or memory span). They can also be based on visual or auditory stimuli (to examine 'simple' or 'choice' reaction times) and on reactions to dynamic stimuli (to analyse psycho-motor performance).

3.6.2.3 Mood and vitality. Target functions relating to mood and vitality have focused generally on behaviours such as sleep and activity (including hyperactivity), as well as feelings of tension, calmness, drowsiness and alertness. These psychological or behavioural states can be assessed either subjectively (with questionnaires and visual analogue scales) or objectively (with electrophysiological, heart rate or blood pressure monitoring systems). Because of the expense and sophistication of electrophysiological instruments, the data gathered on these markers are inevitably restricted to laboratory investigations. Portable continuous monitoring systems for heart rate and blood pressure are ideal for field work.

Changes in mood and vitality as a result of shifts in circadian rhythm (jet lag) are also an important target function.

3.6.2.4 Stress (distress) management. Certain foods or individual nutrients have been implicated in causing or alleviating behavioural stress (or distress). The most appropriate markers for stress states are heart rate, blood pressure, blood catecholamines and skin electrical impedance. With regard to pain, data on blood opioid levels can provide additional useful information.

\subsubsection{Examples of options for modulation}

- Fat, protein and carbohydrates have independent and differing effects on appetite and satiety; protein has been shown to be the most effective, and fat the least 
Table 6. Examples of opportunities for modulation of target functions related to behaviour and psychological functions by candidate food components with possible markers*

\begin{tabular}{|c|c|c|}
\hline Target function & Possible markers & Candidate food components \\
\hline Appetite, satiety and satiation & $\begin{array}{l}\text { reliable direct measure of food intake } \\
\text { indirect measures of food intake } \\
\text { subjective ratings of appetite and hunger }\end{array}$ & $\begin{array}{l}\text { protein } \\
\text { fat replacers } \\
\text { fat substitutes } \\
\text { sugar substitutes } \\
\text { structured fats } \\
\text { specific fatty acids }\end{array}$ \\
\hline Cognitive performance & $\begin{array}{l}\text { objective performance tests } \\
\text { standardized mental function tests } \\
\text { interactive games } \\
\text { multifunction tests }\end{array}$ & $\begin{array}{l}\text { glucose } \\
\text { caffeine } \\
\text { B vitamins } \\
\text { choline }\end{array}$ \\
\hline Mood and vitality & $\begin{array}{l}\text { quality and length of sleep } \\
\text { attitudes (questionnaires) } \\
\text { standardized mental function tests } \\
\text { ratings of subjective states }\end{array}$ & $\begin{array}{l}\text { alcohol } \\
\text { carbohydrates } \\
\text { carbohydrate: protein ratio } \\
\text { tyrosine and tryptophan }\end{array}$ \\
\hline Stress (distress) management & $\begin{array}{l}\text { blood pressure } \\
\text { blood catecholamines } \\
\text { blood opioids } \\
\text { skin electrical impedance } \\
\text { heart rate continuous monitoring }\end{array}$ & $\begin{array}{l}\text { alcohol } \\
\text { carbohydrates } \\
\text { sucrose }\end{array}$ \\
\hline
\end{tabular}

* The information given in this table is derived from the Theme Paper (see Bellisle et al. 1998, S173-S193), where, if not given in this Consensus Document, further details of options for modulations, markers and safety issues can be found.

effective, at suppressing energy intake. Macronutrient substitutes (e.g. fat substitutes and high-intensity sweeteners), because they improve palatability of diets, might, in certain circumstances, also help to control body weight through a reduction in total energy intake.

- There are general beneficial effects of glucose on various aspects of mental performance, including an improvement in working memory, improved decision time, faster information processing and better word recall. Caffeine can also lead to an improvement in most measures of cognitive performance (reaction time, vigilance, memory and psychomotor performance), particularly during the morning.

- High carbohydrate meals help to produce feelings of drowsiness, sleepiness and calmness. In addition, the amino acid tryptophan reduces sleep latency and promotes feelings of drowsiness and fatigue in both adults and children. Tyrosine and tryptophan might help with jet lag but there is only scant scientific evidence for this effect.

- Alcohol, whose intake is both traditional and widespread in Europe, is one of the very few substances to affect all major areas of psychological and behavioural function (appetite, cognitive performance, mood and stress) and the effects are conspicuously dependent on the dose.

- Sweet foods, such as sucrose, might relieve distress in young infants, as might activation of endogenous opioids (b-endorphins) reduce pain perception in the general population.

\subsubsection{Research opportunities}

\subsubsection{Basic science}

- It is crucial to improve the reliability of food intake data. The current methods of measurement, both indirect and direct, are either inaccurate (both under- and overestimations), tedious or expensive. A more accurate and precise method is required, which is not only relatively inexpensive and user/operator friendly but also can be used for large field trials. The use of digital cameras, and the associated computer technology needed for image analysis, might make it possible to measure food intake more reliably under realistic free-living conditions. Patterns of dietary intakes of food components throughout Europe can then be obtained to reflect the cultural diversity.

- Is the ability of alcohol to correct depressive episodes linked, qualitatively and quantitatively, to central neurochemical activity, such as that of serotonin?

3.6.4.2 Cross-sectional and prospective epidemiological evidence

- The large population of Europe, and the ethnic and cultural diversity within it, offer important opportunities to test the validity of laboratory investigations and to study regional differences in psychotropic effects of foods.

\subsubsection{Markers}

- Better measures of cognitive function (memory, reaction time, alertness) are needed. Testing of multiple, rather than independent, responses to nutritional stimuli is necessary to understand the interaction between cognitive processes. This requires development, elaboration and evaluation of methods that can assess operational performance in complex conditions. Driving or flying simulators, and interactive electronic games, are examples of such methods.

- It cannot be assumed that identical foods will exert similar effects in every individual. Methods are needed to identify vulnerable or sensitive individuals. Is it possible to develop genetic markers?

\subsubsection{Human intervention studies}

- Behavioural animal studies are no substitute for human investigations. Data derived from animal studies give, at best, only an insight into the possibility that similar 
phenomena occur in man. Even when a potential effect has been demonstrated in man in the laboratory, it is very important to proceed with appropriate human trials in a free-living situation.

- Most research into behaviour and psychological functions is short term. Extended observations, beyond the immediate effect, are required to see if there is long-term adaptation to the intake of specific food components. In studies on satiety, for example, there are indications that short-term effects of food might weaken with repeated administration.

\subsubsection{Evidence of safety}

- Evidence of safety of food components is particularly important in the study of behaviour since this encompasses intrinsic and extrinsic aspects - the classical biochemical and histopathological changes related to ingestion of specific food components and the changes arising from modification of the person's behaviour or mood. The safety issue of alcohol is a good example of these two aspects.

- In some cases the influence of dietary substances on behaviour and psychological functions involves either doses above those normally consumed in food, or doses causing some degree of nutritional imbalance. The effect of melatonin on circadian rhythms, or of L-tryptophan on sleep, fall within this area.

- Long-term consequences are as important as those observed in the short or medium term. For example, the modulation of eating behaviour through the modification of appetite or satiety should never lead to a deterioration in the general nutrition status of individuals.

\section{TECHNOLOGY ASPECTS OF FUNCTIONAL FOOD SCIENCE (Knorr et al. 1998)}

\subsection{Introduction}

The traditional aim of food processing is to convert raw materials into edible, safe, wholesome, nutritious food products with desirable physico-chemical properties, extended shelf life and optimal features for palatability and convenience of eating. The development of functional foods, however, requires an additional aim - namely, that the functional component (as defined in this document) is either created or optimized (see below). This will require an increased level of complexity and monitoring of food processing.

New raw materials will have to be considered, including those produced by genetic modification and emerging thermal and non-thermal technologies. Safety issues then become increasingly important (e.g. inhibiting transfer of secondary genetic material in genetic modification and effective inactivation of specific components such as toxins, anti-nutrients, micro-organisms, allergens or enzymes by gentle processing techniques).

Integration throughout the entire food chain will also be required to ensure product safety and quality, as well as preservation and/or enhancement of functional components. Sharing of knowledge with scientists in related areas, such as nutrition, is essential to change the traditional pattern of thinking in food science and technology.
The three key areas for technological challenges that have been identified are:

1. The creation of new functional food components in traditional and new raw materials and by de novo synthesis.

2. The optimization of functional food components in raw materials and in foods (e.g. maximal preservation or retention of components, modification of their function and their increased bioavailability).

3. The effective monitoring of the amount and efficacy of functional food components in raw materials and in foods.

Examples will be drawn from the five technology areas covered in the Technology Theme Group papers (i.e. antioxidants, minerals, micro-organisms, carbohydrates and proteins). Some examples of research opportunities (posed as questions in italics) to meet the technological challenges will also be selected from these areas.

\subsection{Examples of technological challenges and research opportunities for the creation of new functional food components}

- To identify viable technologies for the use of new raw materials as sources.

- Can genetic modification be used to increase the antioxidant content of plant foods?

- Can under-utilized and unconventional sources, such as algae and seaweeds, be used as raw materials for the extraction of carbohydrates?

- To produce new classes of functional food components, which can be incorporated into foods and used as substrates for beneficial micro-organisms.

- Can we find a wider spectrum of sources for production of non-digestible oligosaccharides or other carbohydrates? Can we use 'tailored' degradation and transglycolysation of suitable oligosaccharides?

- To generate new functional carbohydrates (e.g. resistant starches and non-digestible carbohydrates) by upgrading raw materials and by-products, which are rich in carbohydrates, using extraction, fractionation and chemical or physical treatments.

- Can the cell wall matrix of the raw plant materials be modified to alter the binding of water, cations and bile salts to polysaccharides? Can new fat replacers be produced in this way?

- To develop the large-scale isolation and enrichment of bioactive peptides and proteins from various raw materials, such as milk and plants, using enzymatic and bacterial hydrolysis using separation and chromatographic techniques.

- Can bioreactors based on immobilized proteolytic enzymes or live micro-organisms be developed?

\subsection{Examples of technological challenges and research opportunities to optimize the amount and efficacy of functional food components}

- To develop economic membrane-processing techniques and to overcome problems of membrane fouling and 
efficiency to obtain maximum recovery of functional food components,

- Is it possible to develop membrane-processing techniques, such as membrane purification for fats and oils to reduce energy consumption, minimize degradation and to maximize stability and antioxidant potential?

- Can we use membrane technologies on food process wastes to recover absorbable mineral complexes with food grade ligands?

- To understand the relationships between packaging environments and antioxidant retention to maximize the functionality of antioxidants in processed foods.

- Can we obtain better data on the antioxidant content of raw materials and of minimally processed foods to ensure their maximal retention?

- What is the impact of controlled and modified atmosphere packaging environments on antioxidant retention?

- To use separation technology to provide specific fractions from raw materials, each with predetermined mineral content and bioavailability.

- Can the controlled separation of skimmed milk from butter preferentially retain important minerals in the skimmed milk?

- To ensure that new minimal processing technologies not only improve the stability of the product, but also retain or improve, mineral availability and allow the release of 'absorbable' minerals.

- Can mineral content, yield, speciation, solubility and bioavailability be improved using gentle physical processes, such as high hydrostatic pressure treatment, ultrasound treatment, high-intensity electric field pulse technology, membrane techniques, fractionation technologies (such as liquid-liquid phase separation for partitioned foods) and enzymic processes (such as malting, fermentation and enzyme addition)?

- To modify fermentation processes for micro-organisms to retain their viability during food processing, storage or preparation and thus provide optimal probiotic function.
- Can non-thermal technologies (e.g. high hydrostatic pressure, supercritical carbon dioxide treatment or high-intensity electric field pulses) be developed to achieve adequate safety, quality, retention and functionality of products containing probiotics?

- To develop probiotics with increased resistance to the environment within the human intestinal tract.

- Is it possible to control fermentation rate in the colon by selecting and developing suitable non-digestible oligosaccharides? Is the fermentability rate due to their degree of polymerization, the type of sugar and glycosidic linkage, the degree of branching or other factors? - Can genetic modification be used to develop highly selective and specific probiotics in terms of their binding properties to intestinal receptors? Can strain selection, fermentation techniques or 'protection' techniques (e.g. by acid-resistant, encapsulated immobilization systems) be used to retain high initial microbial viability and productivity in the intestine?

- Can emerging technologies, such as pressureassisted freezing in conjunction with antifreeze proteins and cryo-protectants, be used as alternatives to conventional freeze-drying of microbial starter cultures for increased viability?

- To optimize the beneficial effects of new carbohydrates (e.g. non-digestible carbohydrates, fat replacers, resistant starch, soluble/insoluble fibre).

- How can the glycaemic index and the resistant starch content be optimized by the careful selection of raw materials and processing conditions?

- To optimize the processing conditions for retaining the activity of bioactive proteins and peptides so that interactions with other food components do not affect the structural/textural quality of food products during processing and subsequent storage.

- What are the effects of conventional versus emerging processing technologies on the bioactivity/ reactivity of proteins and peptides? Can different delivery systems such as liposomes, microencapsulation

Table 7. Examples of technological challenges, with possible solutions and examples of applications, to optimize functional food components*

\begin{tabular}{|c|c|c|}
\hline Technological challenges & Possible technological solutions & Examples of applications \\
\hline $\begin{array}{l}\text { Creation of functional components from raw materials and } \\
\text { from de novo synthesis }\end{array}$ & $\begin{array}{l}\text { immobilized enzyme systems } \\
\text { membrane processes }\end{array}$ & $\begin{array}{l}\text { bioactive peptides } \\
\text { antioxidants } \\
\text { minerals }\end{array}$ \\
\hline $\begin{array}{l}\text { Optimization of functional food components by increasing } \\
\text { their concentrations in raw materials }\end{array}$ & $\begin{array}{l}\text { fermentation, enzyme technologies } \\
\text { non-thermal processes (e.g. high pressure) }\end{array}$ & $\begin{array}{l}\text { minerals } \\
\text { antioxidants }\end{array}$ \\
\hline $\begin{array}{l}\text { Optimization of functional food components through } \\
\text { their modification }\end{array}$ & tailored enzymatic processes & oligosaccharides (fat replacers) \\
\hline $\begin{array}{l}\text { Optimization of functional food components through } \\
\text { increased bioavailability }\end{array}$ & $\begin{array}{l}\text { fermentation technologies } \\
\text { membrane permeabilization processes } \\
\text { (e.g. enzymes, electric field pulses) }\end{array}$ & $\begin{array}{l}\text { micro-organisms } \\
\text { minerals }\end{array}$ \\
\hline $\begin{array}{l}\text { Optimization of functional components in raw materials } \\
\text { and in foods through maximal retention }\end{array}$ & $\begin{array}{l}\text { encapsulation processes } \\
\text { sphere packaging technologies }\end{array}$ & $\begin{array}{l}\text { micro-organisms } \\
\text { bioactive peptides } \\
\text { antioxidants } \\
\text { minerals }\end{array}$ \\
\hline $\begin{array}{l}\text { Monitoring the production of functional foods and } \\
\text { functional components }\end{array}$ & sensors/markers & $\begin{array}{l}\text { micro-organisms } \\
\text { minerals } \\
\text { carbohydrates }\end{array}$ \\
\hline
\end{tabular}

* The information given in this table is derived from the Technology Theme papers (see Knorr et al. 1998), where, if not given in this Consensus Document, further details of technological challenges, possible technological solutions and examples of applications can be found. 
systems and emulsion systems optimize their physiological functions?

- To develop alternative production methods for bioactive peptides and proteins from raw materials to avoid problems such as non-availability, which can occur with conventional processing technology.

- What are the functional properties and interactions of bioactive proteins and peptides in different food systems, e.g. liquid or solid products (i.e. products with high or low water activity)?

\subsection{Examples of technological challenges and research opportunities to monitor the effective production of functional food components}

- To develop efficient technologies to monitor specific functional effects of foods and food components throughout the food chain.

- Is it possible to monitor microbial viability and productivity for optimal probiotic function?

- To improve analytical assays to monitor the availability of functional food components at all stages of processing.

- Can encapsulated minerals and vitamins retain stability in foods during processing as well as being available for absorption in the intestinal tract?

- Can highly specific and sensitive markers be developed that record speciation changes and interactions with food components during processing?

- To develop methods to monitor controlled release and to control bioconversion processes.

- Is it possible to monitor the extent of conversion of individual oligosaccharides and the relevant aspects of the fermentation process?

\section{COMMUNICATION OF THE HEALTH BENEFITS OF FUNCTIONAL FOODS}

\subsection{Introduction}

As the relationship between nutrition and health gains public acceptance and as the market for functional foods grows, the question of how to communicate the specific advantages of such foods becomes increasingly important. Communication of health benefits to the public, through intermediaries such as health professionals, educators, the media and the food industry, is an essential element in improving public health and in the development of functional foods. Its importance also lies in avoiding problems associated with consumer confusion about health messages. Of all the different forms of communication, those concerning the use of 'claims' - made either directly as a statement on the label or package of food products, or indirectly through secondary supporting information - remain an area of extensive discussion. It is therefore essential that claims, which are an inherent part of functional foods, must be based on, and driven by, scientific information.

\subsection{General principles of claims}

The fundamental principle that any claim must be true and not misleading should apply equally to those related to health benefits. All such claims, therefore, should be scientifically valid, unambiguous, and be clear to the consumer. The key issue, however, is how this basic principle should be safeguarded without becoming a disincentive either for the industrial development and production of functional foods (an important determinant in trying to achieve the goal of improved public health) or the acceptance of these foods by consumers (the ultimate target for the functional benefit).

\subsection{Current definitions of claims}

One of the difficulties in the communication of the benefits of functional foods is that the term 'health claim' is defined differently in different countries. The meaning of the word 'claim' itself (as opposed to 'health claim') is, however, generally well understood. A widely accepted definition of a 'claim' is that of Codex Alimentarius (1991). It is defined as 'Any representation, which states, suggests or implies that a food has certain characteristics relating to its origin, nutritional properties, nature, production, processing, composition, or any other quality.'

With the term 'health claim', however, there are some appreciable differences in interpretation. The Food Advisory Committee (of the UK Ministry of Agriculture, Fisheries and Food - MAFF), for example, has defined health claim as 'any statement, suggestion or implication in food labelling and advertising (including brand names and pictures) that a food is in some way beneficial to health, and lying in the spectrum between, but not including, nutrient claims and medicinal claims'. In contrast, in the USA, a health claim refers to any statement 'that expressly or by implication characterizes the relationship of any substance to a disease or health-related condition'. In the UK, therefore, a claim related to a disease would be considered as a medicinal claim whereas in the USA it would be regarded as a 'health claim'.

\subsection{Current classification of types of claims}

The principal difficulty (implied in the above UK definition) in dealing with statements about health benefits is that there are a number of distinct types of claims concerning the association between nutrition and health, and that the definition of them is not the same in all countries.

Codex Alimentarius (1997) has very recently classified and defined some of the different forms of claims. For ease of reference we have called these Types 1-4 and they are:

Type 1. Claims related to dietary guidelines or healthy diets These relate to the pattern of eating in dietary guidelines officially recognized by the appropriate national authority.

Examples: Diets low in saturated fats are recommended by ... ; The advice of ... is to choose a diet high in fibre.

Type 2. Nutrient content claims (subsection of nutrition claims)

These are nutrition claims that refer to the level of a nutrient contained in a food.

Examples: Source of calcium; High in fibre; Low in fat. 
Type 3. Comparative claims (subsection of nutrition claims) These make a comparison of the nutrient level of two or more foods.

Examples: Reduced; Less than; Fewer; Increased; More than.

\section{Type 4. Nutrient function claims (subsection of nutrition} claims)

This is a form of claim that refers to the physiological role of a nutrient in its relationship to growth, development and normal functions of the body. Claims in this category are similar to 'structure/function' claims in the USA. They make no reference whatsoever to a specific disease, pathological state or abnormal condition.

Examples: Calcium might help the development of strong bones and teeth; Contains folic acid; folic acid contributes to the normal development of the fetus.

The above four categories of claims refer to known nutrients and their role in growth development and normal functions of the body. They are, therefore, factual in that they are based on established knowledge that is widely accepted within the scientific nutrition community and make no reference to a particular consequence over and above that expected from the consumption of a balanced diet. Although there is need for research to continue in the areas covered by these claims (to enlarge on the detail of the processes) there is little further necessity to substantiate the concepts themselves.

\subsection{Claims relevant to functional foods}

This EU Concerted Action supports the development of two further types of claims, which are not covered by the above Codex classification and which differ significantly from them. They embrace, but are not restricted to, claims for functional foods. They are based on the scientific classification of markers for target functions that have been developed in this Consensus Document (see Fig. 1 in Section 2). Claims must always be valid in the context of the whole diet and must relate to the amounts of foods normally consumed. This applies to specific effects of foods and food components, both nutrients and non-nutrients.

\section{Type A. 'Enhanced function' claims}

These claims concern specific beneficial effects of nutrients and non-nutrients on physiological, psychological functions or biological activities beyond their established role in growth, development and other normal functions of the body.

This type of claim is also similar to a 'structure/function' claim in the USA and, again, makes no reference to a particular disease or pathological state. However, reference to a mild abnormal condition, as for example indigestion or insomnia, could possibly be permitted.

Examples: Certain non-digestible oligosaccharides improve the growth of a specific bacterial flora in the gut.

Caffeine can improve cognitive performance. Folate can help reduce plasma homocysteine levels.

\section{Type B. 'Reduction of disease-risk' claims}

Claims for reduction of disease risk relate to the consumption of a food or food component that might help reduce the risk of a specific disease or condition because of specific nutrients or non-nutrients contained within it. These claims correspond to those referred to as 'health claims' in the USA.

Examples: Folate can reduce a women's risk of having a child with neural tube defects.

Sufficient calcium intake may help to reduce the risk of osteoporosis in later life.

It is frequently suggested that there should be an additional and specific claim for an improved state of health and well-being. However, since an improved state of health and well-being results from either an enhanced function (physiological or psychological) or from the reduction of risk of disease, it is sufficiently covered by the above two categories.

Satisfactory control procedures are required to ensure that claims are used to their best effect, both for the promotion of public health and protection of the consumer against false and misleading information. Currently Type 1, 2 and 3 claims are generally allowed in most countries. To a much lesser extent, this is also true for Type 4 and Type A claims whilst, in contrast, Type B claims are currently almost universally disallowed (see Section 1).

\subsection{Scientific basis for claims relevant to functional foods}

Perhaps the most pertinent aspect in communication of health benefits is that any claim, or statement, must be based on sound scientific evidence that is both objective and appropriate. However, it is not always clear what constitutes objective and appropriate evidence. One of the major issues to be resolved, therefore, concerns the biological level at which evidence can be accepted as demonstrating functional efficacy.

Data, obtained at several levels of biological organization (molecular, sub-cellular, cellular, tissue, organ, whole body and population level) can be grouped into three types of experimental evidence - biological (biochemical) observations, epidemiological data and intervention trials. All three types of evidence are based on markers. For any given specific food or food component, supporting evidence for functional efficacy might not be available from all three areas. The effectiveness of certain antioxidants in the reduction of risk for cancer, for example, is adequately supported by biological data (at the molecular, sub-cellular and cellular levels), less well supported by epidemiological evidence (at the population level) and hardly at all by clinical intervention trials (whole-body level). In contrast, the effects of dietary fibre are better documented and understood in terms of epidemiology and intervention than they are at the biochemical level.

Whatever judgement or decision is made for establishing proof of functional efficacy, it is important that the required supporting evidence should:

- be consistent in itself;

- be able to meet accepted scientific standards of statistical and biological significance; 


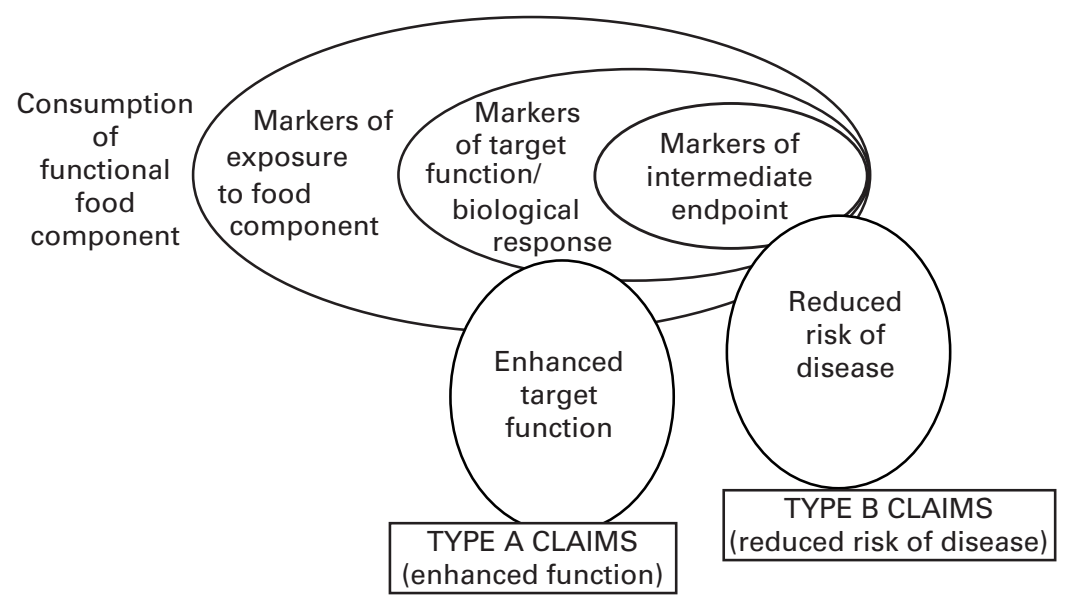

Fig. 2. From scientific evidence based on markers for functional foods to types of claims relevant to them.

- be plausible in terms of the relationship between intervention and results;

- be provided from a number of sources, including human studies.

Clearly, the use of different types of markers can play a very important role in justifying claims. This EU Concerted Action proposes that the classification of markers on the basis of their relationship to the target function or disease endpoint (see Section 2) now offers a scientific approach for the basis of Type A and Type B claims:

If evidence for the effects of a functional food or a functional food component is based on a marker of target function or biological response (functional markers), then a Type A claim (enhanced function claim) might be justified.

A Type B claim (reduced risk of disease claim), however, would only be justified if the evidence for the effect of a functional food or a functional food component is based on an intermediate endpoint marker of disease. This marker would have to be shown to be significantly and consistently modulated by the functional food component for the evidence to be acceptable.

\subsection{Linking the scientific basis of functional foods with the communication about their benefits to the public}

The development of functional foods, with their accompanying claims, will proceed hand in hand with progress in food regulation which is the means to guarantee the validity of the claims as well as the safety of the food. Science in itself cannot be regulated and functional food science provides only the scientific basis for these regulations. At the present time, in several European countries, different initiatives have been taken, based on the dialogue between the food industry,

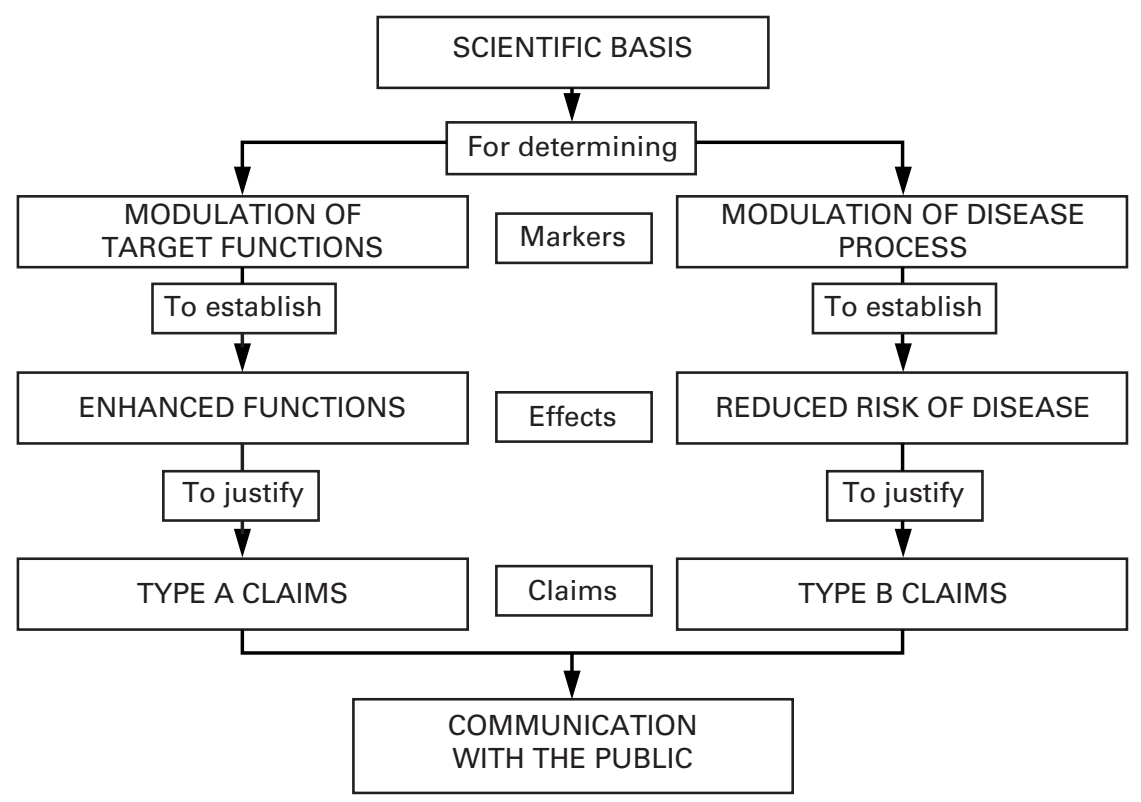

Fig. 3. From the scientific basis for functional foods to communication with the public. 
retailers, regulatory authorities with consumer organizations. A self-regulating programme for 'health claims', which is not independent of existing legislation or the requirements of relevant authorities but would complement both, has been introduced in Sweden and more recently in The Netherlands. It is also being actively considered in the UK and Belgium.

This EU Concerted Action has proposed a scheme whereby the scientific basis of functional food development can be linked to the communication of the benefits of functional foods to the public. This scheme is summarized in Fig. 3. Improved communication with consumers should follow if the principles in this scheme are adopted.

\section{EXECUTIVE SUMMARY}

1. The Functional Food Science in Europe (FUFOSE) project was introduced, evaluated and accepted by the EU DG XII FAIR Programme as a Concerted Action. Its aim was to develop and establish a science-based approach for the emerging concepts in functional food development. Over the last three years of this EU Concerted Action co-ordinated by ILSI Europe, scientific data have been evaluated and new concepts have been elaborated. This Consensus Document is the culmination of the EU Concerted Action and its key points and recommendations are summarized here. It is by no means the end of the process, but, rather, an important starting point and the stimulus for functional food development.

2. Considerable progress has been made in scientific knowledge leading to the identification of functional food components which might eventually lead to an improved state of health and well-being and/or reduction of risk of disease. Consumers are becoming more aware of this development as they seek a betterquality, as well as a longer, life. The food industry has an opportunity to provide products that are not only safe and tasty, but also functional. The originality of the approach in this EU Concerted Action is that it is function-based, rather than product-based. The latter approach would have to be influenced by local considerations of different cultural as well as dietary traditions, whereas the function-based approach starts from the biologically based science that is universal. Furthermore, and most importantly, the functionbased approach in this EU Concerted Action has allowed the development of ideas that suggest a unique way in which to link this scientific basis of functional foods with the communication about their possible benefits to consumers.

3. This EU Concerted Action has adopted the following working definition, rather than a firm definition, for functional foods:

A food can be regarded as 'functional' if it is satisfactorily demonstrated to affect beneficially one or more target functions in the body, beyond adequate nutritional effects in a way that is relevant to either an improved state of health and well-being and/or reduction of risk of disease.
4. Functional foods must remain foods and they must demonstrate their effects in amounts that can normally be expected to be consumed in the diet. They are not pills or capsules, but part of a normal food pattern. A functional food can be a natural food, a food to which a component has been added, or a food from which a component has been removed by technological or biotechnological means. It can also be a food where the nature of one or more components has been modified, or a food in which the bioavailability of one or more components has been modified; or any combination of these possibilities. A functional food might be functional for all members of a population or for particular groups of the population, which might be defined, for example, by age or by genetic constitution.

5. The development of functional foods must rely on basic scientific knowledge of target functions in the body that are relevant to an improved state of health and well-being and/or the reduction of risk of diseases, the identification of validated markers for these target functions and the evaluation of sound scientific data from human studies for their possible modulation by foods and food components. This EU Concerted Action has proposed that markers can be classified according to whether they are markers of exposure to the functional food component, whether they are markers that relate to target function or biological response or whether they are intermediate markers of the actual disease endpoint or health outcome (see Fig. 1).

6. Consumers must be made aware of the scientific benefits of functional foods and this requires clear and informative communication through messages (claims) on products and in accompanying materials. This EU Concerted Action has identified two types of claims that are vital to functional food development and has provided a scientific basis for them to help those who have to formulate and regulate the claims (see Fig. 2).

Claims for 'Enhanced Function Claims' (Type A) should require that evidence for the effects of the functional food is based on establishment and acceptance of validated markers of Improved Target Function or Biological Response, while claims for the Reduced Risk Of A Disease (Type B) should require that evidence is based on the establishment and acceptance of Markers of Intermediate Endpoints of Disease. These markers must be shown to be significantly and consistently modulated by the functional food or the functional food component for either type of claim to be made. This EU Concerted Action has therefore proposed a scheme whereby the scientific basis of functional food development can be linked to the communication of their benefits to the public (Fig. 3). If the principles of such a scheme can be universally adopted, then this should ultimately improve communication to consumers and minimize their confusion.

7. Functional foods must be safe according to all standards of assessing food risk and new approaches to safety might need to be established. This EU Concerted Action proposes that the development of validated 
markers as described above should, if possible, be used and integrated in the safety assessment with particular attention being paid to long-term consequences and interactions between components.

8. The development of functional foods, with their accompanying claims, will proceed hand in hand with progress in food regulation, which is the means to guarantee the validity of the claims as well as the safety of the food. Science in itself cannot be regulated and functional food science provides only the scientific basis for these regulations.

9. The Individual Theme Group papers, which are the science base for this Concerted Action, represent the critical assessment of the literature by European experts (see Bellisle et al. 1998 and Knorr et al. 1998). The health outcomes that have been covered are those related to growth, development and differentiation, substrate metabolism, defence against reactive species, cardiovascular system, intestinal physiology and behavioural and psychological functions.

10. This Consensus Document has selected some examples from each theme paper to illustrate the key target functions for each health outcome with their possible markers and candidate functional food components and has also indicated some research opportunities, technological challenges and safety considerations. Among the technological challenges are issues relating to the creation of new functional food components, their optimization within foods and the continual monitoring of their efficacy throughout food processing.

11. The collaboration between the many disciplines involved in food and nutrition science, such as that which has existed throughout this EU Concerted Action, is essential for successful innovation in functional food development leading to an improved state of health and well-being and/or reduction of risk of disease for consumers.

12. The European Union must play a leading role in the development of, and communication about, functional food science and the European Food industry should share the lead and work in partnership with the scientific community. Support must be given to integrated research programmes aimed at solving the key scientific and technological challenges that have been identified in this Consensus Document.

\section{KEY MESSAGES}

- The food industry has unique opportunities to develop products that are not only nutritional in the traditional sense, but which have additional activity that can lead to an improved state of health and well-being and/or reduction in risk of disease (functional foods).

- Foods can be regarded as functional if they can be satisfactorily demonstrated to affect beneficially one or more target functions in the body, beyond adequate nutritional effects in a way that is relevant to either an improved state of health and well-being and/or reduction of risk of disease. Functional foods must remain foods and they must achieve their effects in amounts that could normally be expected to be consumed in a diet. They are not pills.

- A function-based, rather than a product-based, approach has been proposed whereby the scientific basis of functional foods can be linked to the communication of their benefits to the public. The ability to communicate these benefits is essential for the successful development of functional foods and their role in improving public health.

- Scientific understanding of the way in which components affect body processes involved in health and well-being enables the development of markers that could register the impact of the new food products and could also be used in their safety assessment.

- Evidence from human studies based on markers relating to biological response or on intermediate endpoint markers of disease could thus provide a sound scientific basis for messages and claims about the functional food products. Two types of claims are proposed that would relate directly to these two categories of markers: enhanced function claims, and reduced risk of disease claims.

- Support is needed for integrated research programmes, with interdisciplinary activity, to solve the key scientific and technological challenges and to exploit the scientific concepts in functional food science.

\section{SOURCES OF INFORMATION}

\section{Theme papers}

Bellisle F, Diplock AT, Hornstra G, Koletzko B, Roberfroid M, Salminen S and Saris WHM (1998) Functional Food Science in Europe. British Journal of Nutrition 80 (Suppl. 1), S1S193.

Knorr D et al. (1998) Functional Food Science in Europe. Trends in Food Science and Technology 9, 293-344.

\section{Other references and sources}

Clydesdale FM, Ha Chan S (1996) Proceedings of the First International Conference on East-West Perspectives on Functional Foods. Nutrition Reviews 54, S1-S202.

Clydesdale FM (1997) A proposal for the Establishment of Scientific Criteria for Health claims for functional foods. Nutrition Reviews 55, 413-422.

Codex Alimentarius (1991) Second Edition. Codex General Guidelines on Claims. (CAC/GL 1-1979, rev 1-1991). Geneva, WHO.

Codex Alimentarius (1997) Guideline for Use of Nutrition Claims (CAC/GL 23-1997, Volume 1A, revised). Geneva, WHO.

Food Advisory Committee (1991) Report on its review of food labelling and advertising. Report FDAC/REP/10. HMSO, London.

ILSI Europe (1998) Addition of Nutrients to Foods: Nutritional and Safety Considerations. In ILSI Europe Report Series. Brussels, ILSI Europe.

Institute of European Food Studies (1996) A pan-European Survey of Consumer Attitudes to Food, Nutrition and Health. Dublin, Institute of European Food Studies.

Jonas DA et al. (1996) The Safety Assessment of Novel Foods. In Food \& Chemical Toxicology, Vol. 34, No. 10, pp. 931-940. 